\title{
When Paid Work Matters for Fertility Intentions and Subsequent Behavior: Evidence from Two Waves of the Austrian Gender and Generation Survey
}

\author{
Doris Hanappi, Isabella Buber-Ennser
}

\begin{abstract}
The anticipated risk of job loss and material insecurity are related to fertility postponement in the same way as unemployment is. Given the sequential nature of fertility and occupational decisions, unfavorable working conditions should be resolved before having children, and result in an increase in people's assignment of importance to paid work when developing their childbearing plans. We aim to demonstrate this link, focusing on perceived employment and material insecurity, the importance assigned to paid work in forming fertility intentions, the construction of fertility intentions, and their realization. Using two waves of the Austrian Generations and Gender Survey, we apply probit regressions to analyze gender variations in the associations between uncertainty conditions, the importance of paid work, fertility intentions and behavior. Results reveal that work and related benefits become salient when they are insecure, and that material insecurity among men discourages childbearing. For women, we find support for the hypothesis that the anticipated risk of job loss inhibits the realization of fertility intentions - intentions which are less likely to be constructed under such conditions from the onset of family planning processes.
\end{abstract}

Keywords: Fertility intentions · Realization of intentions · Economic determinants · Austria

\section{Introduction}

The link between economic conditions and fertility is a classic subject in demographic scholarship. Going back as far as the works of Thomas Malthus, much of the empirical literature on the predictors of fertility dynamics is based on the idea that economic hardship and labor market uncertainties will motivate people to postpone or forgo childbearing (Adsera 2011a; Golsch 2003; Sobotka et al. 2011). Since the global economic crisis hit Europe in 2008/9, there has been an increased interest in 
examining the impact of employment uncertainty and material hardship on fertility trends (Goldstein et al. 2013; Hanappi et al. 2017; Kreyenfeld 2015; Testa/GietelBasten 2014; Comolli 2017).

Most studies on the effects of economic uncertainty on fertility date from the pre-crisis era and provide a range of arguments. In these studies, unemployment (Adsera 2011a; Ahn/Mira 2002; Del Bono et al. 2014; Kravdal 2002; Kreyenfeld 2009; Kreyenfeld/Andersson 2014; Matysiak/Vignoli 2008; Pailhé/Solaz 2012; Rondinelli et al. 2006; Schmitt 2012) ${ }^{1}$ and term-limited contracts are in the same way related to fertility postponement as perceived job insecurity, which is in itself an inhibitor to childbearing (Golsch 2003; Gebel/Giesecke 2009; Pailhé/Solaz 2012). Also, female economic uncertainty has received more attention than male economic uncertainty, but the relationship between economic uncertainty and fertility may differ between partners (Hanappi et al. 2017; Kravdal/Rindfuss 2008; Schmitt 2008). How economic uncertainty is associated with fertility may also depend on socio-economic resources. Often, delayed and fewer births result from economic uncertainty that generates high opportunity costs; both motherhood wage penalties (Correll et al. 2007) and lost career advancement opportunities (Rindfuss/Sweet 2013). Stable paid work and responsibly caring for children creates major tensions that were often seen to be responsible for low fertility (Barber 2001; Barber/Axinn 2005; Philipov 2009). These findings stand in contrast to the uncertainty reduction argument, which states that insecure jobs and careers boost fertility. In other words, "the impetus of parenthood is greatest among those whose alternative pathways for reducing uncertainty are limited or blocked" (Friedman et al. 1994: 383). Accordingly, children would compensate for a lack of social integration through paid work by embedding their parents in recurrent social relations. Because job loss is an involuntary experience that people cannot control, it increases the role of paid work in people's perception (Goszczynska et al. 1991). Consequently, people's experience of the risk of job loss raises their awareness of the role of work in their lives, which ultimately affects crucial life decisions, including having children.

This article, therefore, identifies the way in which perceived economic insecurity is linked to people's emphasis on the importance of paid work in fertility decisions (i.e. work salience), to their fertility intentions and behavior over a three-year period. The analysis distinguishes between perceived employment and material insecurity, and examines differences in these associations with work salience, intention formation and its realization. Our analysis addresses three universal questions about the reproductive decision-making process: First, what are the effects of perceived employment and material uncertainty conditions on the importance assigned to paid work in the fertility decision process? Second, do these conditions impede

1 All studies cited here use pre-crisis data, regardless of their publication date. Adsera (2011a), for example, uses 1994-2000 ECHP and 2006 Spanish Fertility Data, Del Bono et al. (2014) analyze 1990-1998 data (Austrian Social Insurance data), Kreyenfeld (2009) uses GSOEP data from 1984-2006, Kreyenfeld and Andersson focus on the pre-crisis years starting in 1980, Pailhé and Solaz use the Familles and Employeur Survey 2004/2005 and Labor Force Survey data until 2008, and finally Schmitt (2012) applies his models to 1994-2001 ECHP data. 
the formation of fertility intentions and do they have repercussions for subsequent fertility behavior? And third, do these relationships differ by gender?

To address our questions, we apply multivariate analyses using the two waves of the Austrian Generations and Gender Survey. Based on Spéder and Kapitány's (2009) analyses, we explicitly focus on short-term fertility intentions, which refer to having a child within three years and follow up on an intention during the respective time period. Our analyses focus on partnered men and women of reproductive age. Employment insecurity as analyzed here refers to a person's concerns of how secure his or her job is, which is in line with the definition of 'cognitive' job insecurity (Anderson/Pontusson 2007; Esser/O/sen 2011). Material insecurity as analyzed here refers to a person's concerns about making ends meet and constitutes a nonmonetary measure of material hardship and an important aspect of material wellbeing (Brady 2003; Sen 2001).

\section{Theoretical background}

Fertility behavior has been shown to be a result of forward-looking and sequential decisions that individuals or households make in an uncertain context under a variety of institutional and economic conditions (Johnson-Hanks et al. 2012; Morgan/ Rackin 2010). Economic conditions not only shape couples' current demand for children, but also their expectations of future resources and, therefore, future demands (Butz/Ward 1979). A vast amount of country-specific studies has revealed significant relationships between economic conditions and fertility in many Western nations such as the US (Cherlin et al. 2013; Grunow et al. 2006; Schneider 2015), Germany, Austria and Switzerland (Bonoli 2008; Gebel/Giesecke 2009; Hanappi et al. 2017; Kreyenfeld 2009, 2015; Sobotka 2011; Sobotka et al. 2011; Vignoli et al. 2012), Italy and Spain (Bernardi 2001; Del Boca/Sauer 2009; Golsch 2003; Martín García 2010), France (Pailhé/Solaz 2012; Thévenon 2010), and the Nordic countries (Andersson et al. 2009; Kravdal 2002).

The recent economic recession in 2008/9 fueled unemployment and economic uncertainty across European countries (Adsera 2011b; Goldstein et al. 2013). By increasing job anxiety (Eichmann/Saupe 2014; Oesch/Lipps 2013) as well as material hardship among the population (Danziger et al. 2012; Treas 2010), it has resulted in a delay of labor market entry and stabilization, hitting younger, less experienced workers and women particularly hard (Cherlin et al. 2013). This development was most evident in countries where the rapid feminization of the labor force was coupled with rigid labor market institutions oriented towards the male prime-aged worker (Adsera 2011b). In these countries - and Austria is no exception to these - childrearing competes substantively for time and energy resources dedicated to paid work (Philipov 2009). In Austria, economic growth has stalled and unemployment has increased from 4.9 percent in 2012 to 5.8 percent in 2015, although both are still comparably low (OECD 2015: 18). The women's labor force participation rate (70 percent) is lower than the men's labor force participation (80 percent; OECD 2017) and with almost every second woman working part-time in 2016 compared to 
only 26 percent in 1994 (Statistik Austria 2016), Austria is the country with the second highest part-time employment rate in the European Union (the EU-28 average was 32.2 percent in 2014 according to Eurostat 2017).

If employment security is threatened at any point in a women's life cycle - typically early in their career, when most human capital accumulation is occurring women may postpone childbearing to acquire experience and/or education and facilitate better wage prospects, benefits, and future employment (Bernardi et al. 2008). Also, women may fear that time spent in childrearing - including staying on maternity leave - may impair their ability to return to and progress in their current employment, and as a result may face the risk of future unemployment and lower wage growth. Lengthy unemployment spells or part-time employment negatively affect household income. Hence, childbearing may become unattractive not only for those directly concerned, but also for those with whom one pools household resources. This relationship has been documented in several single-country studies (Del Bono et al. 2012; Testa et al. 2011; Whelpton et al. 2015). Moreover, employment uncertainty may increase parents' investment per child, in order to increase their future opportunities (Becker 1981).

Standard microeconomic models of fertility suggest that the associated lower opportunity costs turn spells of unemployment and female part-time employment into periods favorable for childbearing (Butz/Ward 1979). Also, insecure employment falls short of providing resources like income and benefits, as well as a sense of belonging, the structuring of daily activities, and social contacts outside the family (Jahoda 1982; Selenko/Batinic 2013), hence, make childbearing an important strategy for uncertainty reduction. Friedman argued that "the impetus of parenthood is greatest among those whose alternative pathways for reducing uncertainty are limited or blocked" (Friedman et al. 1994: 383). Accordingly, children help compensate parents for a lack of social integration through paid work by embedding them in recurrent activities and a network of social relations. Yet, even though children introduce some uncertainties in their parents' life, the fact that parents can control their children's fate, risks and uncertainties more than the fluctuations in labor market conditions makes parenthood the preferable option to struggling on the labor market (Friedman et al. 1994).

People downplay uncertainties that they experience voluntarily and can control (such as parenthood), whereas involuntarily and uncontrollable uncertainties seem more daunting in their perception (Goszczynska et al. 1991). Consequently, the risk of involuntary job loss and lower wage growth would increase people's perception of the importance of paid work in their lives, which would ultimately affect major life decisions including having children (Selenko/Batinic 2013). In the work-family conflict literature, the concept of work salience expresses the importance of the work role to a person (Greenhaus et al. 1989). Independent of the pressures experienced due to characteristics of the job, the role, and the work schedule, work salience relates to conflicts between paid work and family roles. Moen $(1985 ; 2008)$ also argued that the "absorptiveness" of jobs, and one's emotional involvement in one's occupation or career constitutes a significant source of intrusion of work into the family domain. Highly involved workers who are preoccupied with their jobs and 
achieving success in their work domain are more likely to devote greater effort and energy to the work role, thereby experiencing increased stress levels and tension between work and family (Esping-Andersen 2009; Hakim 2003). Empirical evidence is provided in numerous recent studies on well-being (De Cuyper/De Witte 2006; De Cuyper/Isaksson 2017; Lent/Brown 2008) but to a far lesser extent on fertility (Buber-Ennser/Fliegenschnee 2013). In sum, one would expect a positive relationship between employment uncertainty and the importance of paid work for fertility decisions.

The fertility response to economic insecurity among persons of reproductive age indicates the existence of a decision-making process (Blossfeld/Hofmeister 2007). The Theory of Planned Behavior (TPB) by Ajzen and Fishbein (Ajzen 1991; Ajzen/Fishbein 2005) has been used for analyzing fertility decisions and intentions (Billari et al. 2009; Dommermuth et al. 2015; Mencarini et al. 2015). According to the TPB approach, intentions - in our case, fertility intentions - are described as being directly dependent on three conceptually independent determinants: attitudes towards the behavior, social norms, and perceived behavioral control. For instance, behavioral control is seriously jeopardized in times of employment insecurity and the related threat of involuntary job loss. Background factors (e.g. individual factors such as personality, age, and education) influence the construction of intentions by affecting attitudes, subjective norms and perceived behavioral control (Ajzen) Fishbein 2005). Intentions are a major element of the decision to have a child or not (Johnson-Hanks et al. 2012; Miller/Pasta 1995; Miller et al. 2004), though fertility intentions do not always match actual fertility at an individual level (Quesne/-Vallée/ Morgan 2003). That notwithstanding, studying fertility intentions helps us understand why people do or do not develop childbearing plans, and their subsequent behavior (Léridon 1995). The better we understand factors in the development of fertility intentions, the better we will understand the corresponding behavior. Unlike lifetime intentions (i.e., intended family size) and the intention to have any more children at all, short-term intentions refer to the intention to have a child within a two- to three-year period (Philipov/Bernardi 2011). Over such a timespan, respondents can gauge their life conditions and any obstacles that might hamper them from realizing their intentions more easily. Short-term intentions are therefore considered to be strongly linked to external conditions and to the attributed salience of these conditions for childbearing (in our case, the importance of paid work); that is, people may refrain from developing an intention to have a child in the light of unfavorable conditions or not realize a childbearing intention over the course of two or three years.

\section{The Austrian context}

This paper focuses on Austria, a country where stable low fertility rates (e.g. the 2015 TFR was 1.5) and high rates of childlessness correlate with a highly gendered labor force participation (OECD 2015). The conservative welfare regime has prompted lengthy parental leave periods for women after childbirth, with strong repercussions on their labor market behavior (OECD 2015) and organizations' hiring practices 
(Buber/Neuwirth 2009; Lalive/Zweimüller 2009; Wernhart/Neuwirth 2007). While men mostly work fulltime, women mostly work part-time (Sobotka 2011) in noncareer track jobs that often generate low permanent income through slow income growth and less human capital accumulation (Adsera 2011b). In addition, paid maternity leave before and after childbirth was a maximum of $30(+6)$ months in 2002, with other options being $15(+3)$ and $20(+4)$ months (Kreimer 2011; Prskawetz et al. 2008). The figures in brackets indicate the additional months granted if the parents share the leave. Further changes in 2017 allow more flexibility by allotting parents a certain amount of parental leave payments that they are free to spend (BMFJ 2016). Under current Austrian legislation, the leave period is not identical to the job protection period, which ends at the child's second birthday (see Berghammer 2014). Beneficiaries receive flat-rate payments during the leave period. This particularly benefits low-income women, for whom the earnings replacements ratio is relatively high, but the low amount paid does not fully substitute a wage, nor is it enough to live off on its own. Shorter variants with higher monthly payments, which were introduced in 2008, are typically taken by higher educated women. Entitlements to part-time leave have been in effect since 1990, thereby fostering maternal part-time work. Starting from 2004, parents who had been working in a company with more than 20 employees for at least three years have been entitled to work part-time until their child's seventh birthday (Berghammer 2014; Kreimer 2011; Prskawetz et al. 2008). At the same time, policies for balancing child care and full-time employment are limited: While the public kindergarten system is well established, with 84 to 98 per cent of three- to five-year-olds enrolled in formal care in 2012/13 (OECD 2015), only one third of all childcare places for this age group allow parents to reconcile family demands with full-time work (Festl et al. 2010). Childcare infrastructure for children under the age of three is underdeveloped, and although the enrolment of children of this age group has increased substantially in the last years, it is at a low level (23.3 percent in 2013) (Buber-Ennser 2015; OECD 2015). In such a context, perceived employment and material insecurity may be caused by concerns about losing one's job, or by (especially) women's concerns about facing difficulties to balance paid work with childrearing and care duties.

\section{$4 \quad$ Hypotheses}

As outlined above, individuals who experience employment insecurity and material hardship might be less likely to have children, not realize an existing childbearing intention, and not even construct concrete family plans (Adsera 2011b; Begall/Mills 2011; Grunow et al. 2006; Hanappi et al. 2016; Kreyenfeld et al. 2012; Spéder/Kapitány 2009, 2015). We add to this the consideration that such conditions may have a direct effect on paid work being perceived as important when clarifying intentions. The links that we are interested in are visualized in Fig. 1, our hypotheses are formulated accordingly. Line 1 presents the link between the perceived employment and material insecurity and the self-rated salience of work for the construction of a fertility intention, line 2 shows the link between these insecurity dimensions and the 
Fig. 1: Schematic presentation of the relationship between job insecurity, work salience, and the formation of concrete childbearing intentions and subsequent behavior

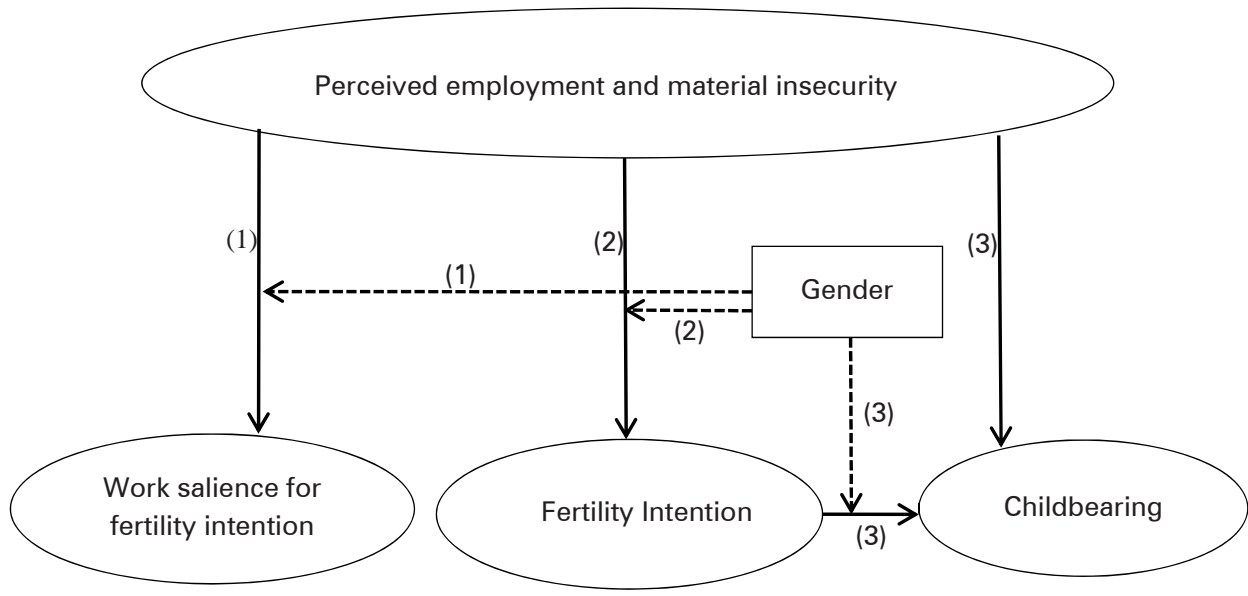

Source: Own design

construction of an intention to have a child in the near future, and line 3 illustrates the link between job insecurity and intentional childbearing. We expect these relationships to vary by gender.

In the first case, we recall the argument that short-term intentions are strongly linked to external conditions and to the attributed salience of these conditions for childbearing (in our case, the importance of paid work). Since research has demonstrated that in the light of unfavorable conditions people refrain from developing the intention to have a child or do not realize childbearing intentions in the course of two to three years (Morgan/Rackin 2010; Philipov/Bernardi 2011), we examine whether employment insecurity and material hardship (termed "material insecurity" hereafter) increase the likelihood that paid work matters for developing childbearing intentions. In other words, we examine the role of employment and material insecurity for work being perceived as salient for the construction of short-term fertility intentions (line 1). Suppose that individuals want to have a child: In this case, microeconomic models suggest a mobilization of time and energy to improve their economic situation, and to secure material resources. According to Adsera (2011b), a shortage of resources can be resolved by prioritizing paid work over childbearing, i.e. by postponing family plans and thus adapting the sequencing of transitions (Bernardi et al. 2008). In this case, individuals facing employment insecurity are expected to assign high importance to paid work, because the desire to have secure employment as a favorable condition to fertility is not yet met and efforts to reduce insecurity in the work domain require considerable time and energy. Instead, if individuals experience economic security, and have not yet reached their personal fertility goals, their work salience will be low because economic conditions regard- 
ing developing the intention to have a child are favorable. We therefore formulate the following hypothesis:

(1a) Employment insecurity increases the likelihood of paid work being valued as important for one's intention to have a child.

As discussed earlier, the threat of future job loss exerts not only direct job strain on individuals but also material insecurity on households, especially when they pool financial resources (Del Bono et al. 2012; Testa et al. 2011; Whelpton et al. 2015). In analogy to perceived employment uncertainty, we expect that individuals who experience material insecurity assign a greater importance to employment when developing fertility intentions. Given the sequential ordering of events, individuals assign priority to securing material resources. We therefore hypothesize:

(1b) Material insecurity increases the likelihood of paid work being valued as important for one's intention to have a child.

In the second case, we examine the association between employment and material insecurity and the likelihood of developing a positive fertility intention (line 2). We derive our hypothesis from prior research on major determinants of fertility intentions attributing importance to socio-economic factors (Billari et al. 2009; Dommermuth et al. 2011; Hanappi et al. 2017; Kuhnt/Trappe 2016). Moreover, substantive gender differences in the reaction to declining employment uncertainty have become evident (Hanappi et al. 2017). This suggests taking into account differences in gender roles for the following reasons: When men work under employment insecurity or have difficulties making ends meet, their income may not suffice to support the family, and therefore threatens intention formation and realization (Modena/Sabatini 2012; Neyer et al. 2013; Sobotka/Testa 2008). Hence men's economic uncertainty is likely to discourage them from having children. Women's employment uncertainty may threaten the intention of having a child too, but at the same time, lower opportunity costs make childbearing and the related social rewards an attractive option. Accordingly, employment and material insecurity hamper the capacity of men and women (as mostly the secondary earners) to support the family, and thus affect fertility intentions and their realization. We expect the association between employment insecurity and the construction of fertility intentions to be negative among men and positive among women. In contrast, material insecurity - as a major manifestation of material deprivation (Castel/Dörre 2009) - is a more severe form of uncertainty, which affects entire households and thus both men and women in their fertility decisions. However, women have been shown to be more ambivalent in their fertility response to external conditions, one reason of which is their shorter reproductive life span and existing age norms (Mynarska 2010). In the subsequent analysis, we seek to confirm these gender-specific links between perceived employment insecurity and material insecurity and positive fertility intentions with data from Austria. These are the corresponding hypotheses: 
(2a) Employment insecurity discourages positive fertility intentions among men, and encourages fertility intentions among women.

(2b) Material insecurity discourages positive fertility intentions among men, and to a lesser extent among women.

In the third case, we examine the relationship between employment and material insecurity, and the likelihood of intentional childbearing (line 3). Purveyors of the Theory of Planned Behavior (Ajzen 1991; Ajzen/Fishbein 2005; Ajzen/Klobas 2013) argue that intentions are influenced by perceived behavioral control, in our case, the lack of it (i.e. involuntary job loss creates a certain lack of control). In the subsequent empirical analysis, we test whether individuals realize their fertility intentions depending on the above conditions. In other words, we test whether conditions of economic insecurity interfere with subsequent fertility behavior or whether once an intention is set, realization is simply the natural next step. In line with previous literature (Jalovaara et al. 2017; Neyer et al. 2013), we expect gender effects to point in similar directions as the ones outlined above for fertility intentions. Women's opportunity costs can be compensated by various factors such as social support by family and friends in childrearing; and child allowances or maternal leave could be attractive, particularly to women with lower levels of education (Friedman et al. 1994). In these and similar situations, women's employment insecurity may facilitate rather than constrain behavior. We therefore formulate the following hypotheses:

(3a) Male employment insecurity decreases the likelihood of the intention to have a child to be realized. Female employment insecurity increases the likelihood of the intention to have a child to be realized.

(3b) Male material insecurity decreases the likelihood of the intention to have a child to be realized. For female material insecurity, we expect this association to be weaker.

\section{$5 \quad$ Data and methods}

\subsection{Data}

The current study is based on the Austrian Generations and Gender Survey (GGS) as part of the Generations and Gender Programme. Within this programme, largescale representative surveys have been conducted in 17 European countries, as well as in Australia and Japan, since 2001. The GGS is designed as a panel survey consisting of three waves carried out at intervals of three years. In Austria, the first wave was conducted in 2008/9 and the second wave in 2012/13, thus with a period of four years between the waves due to financial reasons. About five thousand respondents were interviewed in the first wave, about 3,900 in the second wave. The data contain complete family and fertility histories and a rich set of socio-economic 
variables. The response rate in wave 1 was 61 percent (Statistik Austria 2009), available weights adjust for age, sex, employment status, country of birth, living arrangements and parity (Buber 2010). In wave 2, panel attrition was rather modest, amounting to 22 percent (Buber-Ennser 2014). Panel data are affected by a small bias towards family-oriented persons as well as a higher attrition of less educated respondents and persons with migration backgrounds, but the data can nonetheless be used without (larger) concerns about selectivity (Buber-Ennser 2014).

For the current study, the final sample included 1,778 women and 1,128 men aged 18 to 44 years who participated in both waves, have a partner (either cohabiting or living apart-together), and with valid information on fertility intentions for the next three years. As the partnership context is important for realizing fertility intentions, we excluded persons with short-term fertility intentions but without a partner.

\subsection{Measures}

Our hypotheses require three main dependent variables. First, for our hypotheses testing the role of perceived economic insecurity for paid work being considered as important for the construction of the fertility intention (work salience; line 1), the main dependent variable is own work important for plans to have a child measured at wave 1. The exact wording of the question was "How much would the decision on whether to have or not to have a(nother) child during the next three years depend on your work?" The importance was measured by an ordinal scaled variable, where higher numbers indicate higher importance. Possible answers were "not at all (1)", "a little (2)", "quite a lot (3)" and "a great deal (4)". Answers were coded into a dichotomous variable, distinguishing between "important" (when answering "quite a lot" or "a great deal") and "not important" (when choosing "not at all" or "a little").

Second, for our hypotheses regarding how perceived economic insecurity is related to fertility intentions (line 2) we used information on intentions in wave 1, based on the question "Do you intend to have a(nother) child during the next 3 years?" Possible answers (Definitely no, probably no, probably yes, definitely yes) were dichotomized between "yes" and "no". Because individuals can anticipate how economic conditions in the short-run will affect their childbearing plans, short-term intentions are effective in capturing the impact of external conditions such as anticipated job loss on fertility behavior.

Third, for our hypotheses regarding how perceived economic insecurity is related to intended births (line 3), we combined information on intentions in wave 1 and on newborn babies between wave 1 and wave 2 . We concentrated on those 473 women and 363 men who intended to have a child within the next three years at wave 1. Short-term fertility intentions correlate positively with subsequent childbearing behavior at the individual level (Ajzen 1991; Miller/Pasta 1995). By regressing explanatory variables for intended births only, we avoid overestimating the associations between perceived economic insecurity and behavior.

All of the following explanatory variables were assessed in the wave 1 interview in 2008/9. Our variables for the respondents' perceived economic insecurity, here referred to as economic concerns, are: 
- "Concerns about job insecurity" built as follows: Employed persons ${ }^{2}$ were asked to rank their satisfaction with job security on a scale ranging from 0 (not at all satisfied) to 10 (very satisfied). We then grouped respondents into three categories taking into account size of cells and regression coefficients of similar size, distinguishing between (1) employed and very low satisfaction $(0$ to 4$)$, (2) employed and medium satisfaction (5 to 8) and (3) employed and high satisfaction (9 to 10). Our models also account for alternative employment statuses including (4) self-employed, (5) unemployed, (6) student (or in education), (7) parental leave, (8) housekeeping, and (9) other.

- "Concerns about making ends meet" measured by the question "How difficult is it to make ends meet?". Answer categories ranged from (1) with great difficulty, (2) with difficulty, (3) with some difficulty, (4) fairly easily, (5) easily, to (6) very easily. Because this variable captures perceived financial difficulties in making a living, we included it in our models to account for existential, material needs in addition to the concerns of job insecurity.

Previous research has identified factors relevant for fertility decisions and behavior, such as age (Gustafsson 2001), parity (Berrington/Pattaro 2014) and education (Korpi 2000; Kravdal/Rindfuss 2008; Neyer/Hoem 2008; Rindfuss et al. 1996; Rossier/Bernardi 2009; Spéder/Kapitány 2015). These socio-demographic factors were included as control variables (measured at wave 1):

- "Number of children": (1) childless, (2) one child, (3) two children, and (4) three or more children. Firstborn children have the greatest effect on parents' lives (Nomaguchi 2012). Moreover, intending to have or having a second child is much more likely in contexts where the two-child norm dominates (Goldstein et al. 2003).

- "Age": 18-19, 20-24, 25-29, 30-34, 35-39, 40-44 years.

- "Education": Low (lower secondary), medium (higher secondary) and high (tertiary) level. Higher education is a proxy for a higher personal income as well as for stronger personal resources and support networks, particularly among women (Bernardi et al. 2008). Because educational attainment is a strong marker of socioeconomic status and resources to mitigate job insecurity, including education in our models should reduce the effects of our explanatory variables.

- "Sex": It was taken into consideration either as a control variable in the pooled sample including both sexes, or via separate analyses for women and men to allow for different effects according to sex.

\subsection{Method}

We start by providing descriptive results on the importance of one's paid work for the intention to have a child within the next three years and on childbearing plans for the next three years. Next, we apply multivariate analyses to examine the factors associated with regarding one's own work as important for the construction of the fertility intention (line 1), fertility intentions (line 2), and their realization (line 3). In a

$\overline{2}$ Self-employed persons were not asked for their satisfaction with job security. 
first set of analyses, we study the role of paid work in the construction of short-term fertility intentions. We ran probit regressions with the importance of paid work for the intention to have a child during the next three years as a dependent variable ( 1 if "quite a lot" and "a great deal" and 0 otherwise). In a second set of analyses, we focus on short-term intentions and aim to identify possible associations with employment and material insecurity (line 2). In a last step, we test whether individuals who perceive employment and material insecurity are more likely to have a child or not (line 3), using the longitudinal nature of the GGS. Therefore, the dependent variable is the realization of short-term fertility intentions, derived from wave 2 of the survey (equaling 1 if a child was born within the first or second wave or if the respondent was expecting a child at wave 2). A combination of employment status and satisfaction with job security as well as self-perceived material insecurity are the main explanatory variables.

Multivariate analyses are based on probit models, which can be described as nonlinear regression models with a binary dependent variable $Y$. The variable $Y$ is assumed to depend on $k$ observable variables $X_{1}, \ldots, X_{k}$ and on a disturbance term $u$, written as $Y=\sum \beta_{k} X_{k}+u$. The question of interest is the probability that $Y$ equals 1 , mathematically $P(Y=1)=P\left(Y=1 \mid X_{1}, \ldots ., X_{k}\right)$, or simply $P(Y=1 \mid X)$. The standard probit model is given by $\mathrm{P}(\mathrm{Y}=1 \mid \mathrm{X})=\Phi\left(\sum \beta_{\mathrm{k}} \mathrm{X}_{\mathrm{k}}\right)$ (A/drich/Ne/son 1986). The unknowns are the parameters $\beta_{k}$ and we apply the software STATA for their estimation, using a Maximum Likelihood Estimation. The observable variables $X_{1}, \ldots ., X_{k}$ represent material and employment insecurity and socio-economic characteristics as control variables.

\section{Descriptive results}

We start our analysis with descriptive statistics regarding dissatisfaction with job security, fertility and work intentions, and whether work is important for developing concrete childbearing plans (i.e., work salience) and ultimately realizing these.

\subsection{Job insecurity and employment status}

In our sample, roughly seven in ten women and eight in ten men were employed at the time of the first wave (Table 1). Only four in ten men and women were employed and very satisfied with their job security. 28 percent of women and 36 percent of men were employed and perceived some dissatisfaction with job security (Table 1, left columns). Self-employment was more frequent among men than women (11 percent versus 7 percent), unemployment (2-3 percent) and enrollment in education (5-6 percent) was rare. Some of the women were on parental leave (8 percent) or looking after the home and family (6 percent), whereas the share of men on parental leave was less than 1 percent. Further activities, such as military or social service, as well as being permanently ill or disabled, amounted to 1 percent among women and 3 percent among men. Focusing on employed persons only, we found that women were more often very satisfied with their job security than men 
Tab. 1: Sample by employment status, satisfaction with job security and sex

\begin{tabular}{|c|c|c|c|c|c|c|}
\hline & \multicolumn{3}{|c|}{ Full sample } & \multicolumn{3}{|c|}{ Employed persons only } \\
\hline & Women & Men & $\begin{array}{l}\text { Total } \\
\text { in }\end{array}$ & $\begin{array}{l}\text { Women } \\
\%\end{array}$ & Men & Total \\
\hline Self-employed & 7 & 11 & 9 & & & \\
\hline Unemployed & 3 & 2 & 3 & & & \\
\hline Student & 6 & 5 & 6 & & & \\
\hline Parental leave & 8 & 0 & 4 & & & \\
\hline Housekeeping & 6 & 0 & 3 & & & \\
\hline Other & 1 & 3 & 2 & & & \\
\hline $\begin{array}{l}\text { Employed, low satisfaction with } \\
\text { job security }\end{array}$ & 5 & 4 & 4 & 7 & 5 & 6 \\
\hline $\begin{array}{l}\text { Employed, medium satisfaction } \\
\text { with job security }\end{array}$ & 23 & 32 & 27 & 33 & 41 & 37 \\
\hline $\begin{array}{l}\text { Employed, high satisfaction } \\
\text { with job security }\end{array}$ & 41 & 43 & 42 & 60 & 54 & 57 \\
\hline Total & 100 & 100 & 100 & 100 & 100 & 100 \\
\hline N (unweighted) & 1,788 & 1,131 & 2,919 & 1,106 & 894 & 2,000 \\
\hline
\end{tabular}

Note: Low satisfaction with job security (0-4 on 0 -10-scale); medium satisfaction (5-8); high satisfaction (9-10).

Source: Austrian GGS, partnered persons aged 18-44, weighted data

were (60 percent versus 54 percent), and slightly more often reported very high dissatisfaction (7 percent versus 5 percent) (Table 1, right columns). As the confidence intervals overlap, we did not find that women reported very high dissatisfaction significantly more often than men. ${ }^{3}$

\subsection{Work salience and economic insecurity}

We now turn to the importance of one's paid work for developing a fertility intention in the near future. Because perceptions of job insecurity might be mediated by objective conditions (e.g., entitlements to leave or part-time work) and the cognitive evaluations of them, it is vital to grasp how salient paid work is for developing concrete childbearing plans. It turns out that women perceive their paid work to be relevant for family plans more often than men do (Table 2): For more than one third of Austrian women, their own paid work is relevant for their intention to have a child in the near future, whereas for four in ten it is not at all important. Among men, 20 percent perceive the own job to be important for short-term fertility intentions, and

3 In contrast, employed women stated significantly less often than employed men a medium level of satisfaction. 
Tab. 2: Importance of one's own paid work for plans to have a child within the next three years, by sex

\begin{tabular}{lccccc|c}
\hline & Not at all & A little & $\begin{array}{c}\text { Quite } \\
\text { a lot } \\
\text { in \% }\end{array}$ & $\begin{array}{c}\text { A great } \\
\text { deal }\end{array}$ & Total & Mean1 \\
\hline Women & 42 & 22 & 20 & 16 & 100 & 2.1 \\
Men & 55 & 26 & 14 & 6 & 100 & 1.7 \\
Total & 48 & 24 & 17 & 11 & 100 & 1.9 \\
\hline
\end{tabular}

1 not at all (1), a little (2), quite a lot (3) and a great deal (4)

Source: Austrian GGS, 2,908 partnered persons aged 18-44, weighted data

more than half assign no importance at all to the own job (55 percent). The mean level of importance was higher for women than for men (2.1 and 1.7, respectively).

We now add the aspect of employment insecurity and differentiate employees by their satisfaction with job security. It turns out that especially for employed women with a low satisfaction with job security as well as for women in education, paid work is important for childbearing plans for the near future (Fig. 2). In contrast, women highly satisfied with their job security substantially less often rated paid work as an important factor for their short-term family plans. Among men, we find a similar but less pronounced pattern for the association between satisfaction with job security and fertility decisions, with employed men who are highly satisfied with their job security more often stating that their own work is not important for the decision to have a child (63 percent) as compared to those with medium or low levels of satisfaction (51 percent and 52 percent) (Fig. A1). As is the case for women, paid work is relevant for short-term fertility decisions for men enrolled in education. Moreover, paid work is rather important for unemployed men, although this group is small in number. Enrollment in education and unemployment indicate material insecurity.

Finally, material insecurity measured via difficulties in making ends meet is relevant for the likelihood of paid work being valued as important for short-term fertility plans: Women and men perceiving (great) difficulties in making ends meet more often stated that their paid work is important for the decision to have a child, compared to those perceiving only some difficulties and those making ends meet fairly easily or (very) easily (Fig. 2 and A1). 
Fig. 2: Importance of one's own paid work for the decision to have a child during the next three years by employment status and satisfaction with job security and by making ends meet, women

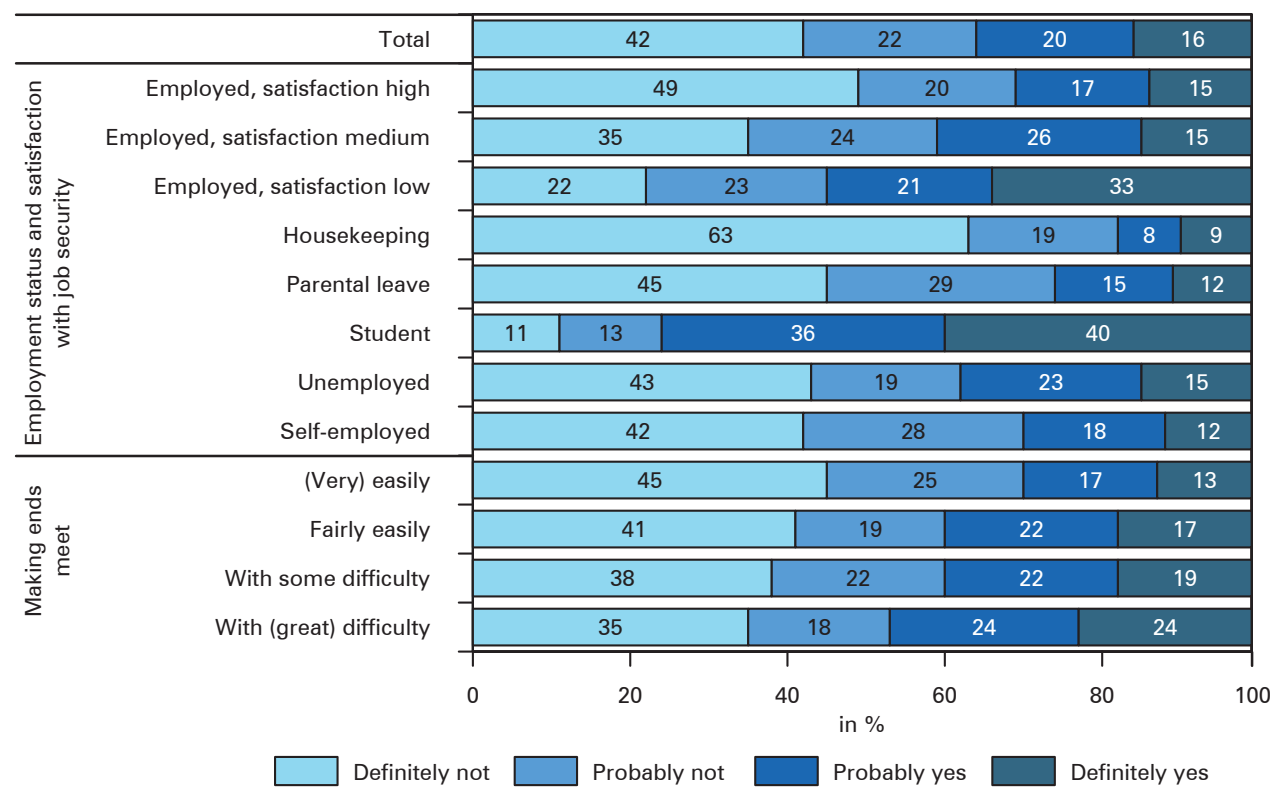

Note: Low satisfaction with job security (0-4 on 0-10-scale); medium satisfaction (5-8); high satisfaction (9-10).

The category "other (employment status)" is not shown because of small numbers of cases $(n=18)$.

Source: Austrian GGS, 1,778 partnered women aged 18-44, weighted data

\subsection{Paid work and family planning}

Overall, roughly three out of ten women and men aged 18 to 44 years (and who had a partner) intended to have a child within three years. Men and women reporting low satisfaction with job security intended more often to have a child within the next three years compared to their peers who were satisfied with their job security (41 percent and 45 percent versus 32 percent and 27 percent) (Table 3 ). This suggests that parenthood might be a valuable alternative to pursuing an insecure occupational career, while stable employment competes with concrete childbearing plans. Because motherhood entails a longer absence from the labor market, opportunity costs for women (e.g. missed promotions and forgone salary increases) are substantial. As expected, family plans for the near future are rare among students or persons in other forms of educational or occupational training. An aspect contingent to Austria's employment and parental leave system is that a substantial proportion of women on maternity leave (almost 40 percent) intended to have a 
Tab. 3: Intention to have a child within the next three years, by sex

\begin{tabular}{lcc}
\hline & Women & Men \\
& \multicolumn{2}{c}{ in \% } \\
\hline Self-employed & 27 & 33 \\
Unemployed & 27 & 30 \\
Student & 18 & 14 \\
Parental leave & 39 & - \\
Housekeeping & 14 & - \\
Other & 24 & 22 \\
Employed, low satisfaction with job security & 45 & 41 \\
Employed, medium satisfaction with job security & 28 & 32 \\
Employed, high satisfaction with job security & 27 & 31 \\
Total & 28 & 32 \\
\hline
\end{tabular}

Note: Due to small numbers of men on parental leave or housekeeping (1 and 2 respectively), the share of those intending a child is not given in the table.

Source: Austrian GGS, 2,919 partnered persons aged 18-44, weighted data

child within the next three years (Table 3). Further parity-specific analyses show that, with a proportion of 75 percent, mothers with one child who were on maternity leave very often intended to have a (second) child within three years. This is in line with a strong two-child norm in Austria and a desire to rather closely space first and second children.

Focusing on men and women intending to have a child within the next year at wave 1, it turns out that 43 percent among them had a newborn at wave 2, or were expecting a child. The remaining group either postponed their fertility intentions and still wanted a child (37 percent), whereas a substantial share ( 20 percent) had abandoned their further childbearing plans and did not want to have (further) children at wave 2. In this paper, we do not further elaborate on the aspect of postponement or abandonment of short-term fertility intentions and focus on the realization of the latter in a multivariate framework, without providing descriptive results.

\section{$7 \quad$ Multivariate results}

The above mentioned bivariate effects may be driven by factors such as age, education, and family cycle, which impact how individuals rate the salience of work in forming family plans and how they perceive job insecurity. We therefore apply a multivariate approach. First, we examine how economic concerns are related to the importance of paid work for the construction of the fertility intention (line 1). We ran probit regressions with the importance of paid work for the intention to have a child during the next three years as a dependent variable (1 if "quite a lot" and "a great deal" and 0 otherwise) (Table 4). Second, we analyse whether individuals who 
perceive economic insecurity are more or less likely to intend to have a child in the near future (line 2, Table 5). Third, we test whether individuals who perceive economic insecurity are more likely to have a child or not (line 3), using the two waves of the GGS (Table 6). A combination of employment status and satisfaction with job security as well as self-perceived economic constraints are the main explanatory variables.

\subsection{Economic insecurity and work salience in fertility decisions}

Analyses testing how employment insecurity (hypothesis 1a) and material insecurity (hypothesis $1 \mathrm{~b}$ ) are related to the perceived salience of paid work for fertility decisions were run for men and women separately (Table 4). Positive coefficients indicate that paid work is considered an important aspect for the decision to have a child.

Four results are noteworthy: First, the current employment situation and the associated perceived job insecurity are crucial for paid work being valued as important for the decision to have a child in the near future. Employed persons who were very satisfied with their current job security were the reference group. Results show that for employed women who were somewhat or quite concerned about job insecurity (i.e. with a middle or low level of job satisfaction), their paid work was significantly more often important in the fertility decision process. The estimated coefficients indicate a negative association: the lower the satisfaction, the higher the importance of their paid work for fertility decisions. For men, satisfaction with job security also has an effect, although it is smaller in size and at a lower level of statistical significance. Our multivariate results thus support hypothesis 1a, which assumes that employment insecurity increases the likelihood of work being valued as important for one's intention to have a child. Second, being enrolled in education matters: Women and men in education rated their own (future) work as particularly important for their decision to have a child, as the size and statistical significance of the estimated coefficient indicate (Table 4). Third, material insecurity is significantly associated with the relevance of one's own job for fertility intentions: Women and men perceiving major economic constraints more often regarded paid work as important for family plans, whereas those making ends meet easily or very easily were less likely to evaluate their paid work as important for family plans. Our results thus support hypothesis $1 \mathrm{~b}$ that material insecurity increases the likelihood of work being valued as important for one's intention to have a child. Fourth, sociodemographic characteristics matter: One's own work is important in the fertility decision process among women with two children, among women below the age of 20, and especially among highly educated women. Among men, the importance of paid work varies according to age, and is crucial especially below the age of 30 . Educational level is significantly associated with the importance of work for family plans and effects men in a similar way as women, whereas the number of children has no explanatory power. 
Tab. 4: Estimated coefficients for one's own work being important for plans to have a child during the next three years

\begin{tabular}{|c|c|c|c|c|}
\hline & Women & Men & $\begin{array}{l}\text { Women } \\
\mathrm{N}\end{array}$ & $\begin{array}{c}\text { Men } \\
\mathrm{N}\end{array}$ \\
\hline \multicolumn{5}{|c|}{ Employment status and satisfaction with job security } \\
\hline Self-employed & -0.18 & -0.17 & 120 & 120 \\
\hline Unemployed & 0.21 & 0.74 & 65 & 24 \\
\hline Student & $1.39 * * *$ & $2.05^{* * *}$ & 101 & 60 \\
\hline Parental leave & $-0.49 *$ & - & 218 & 0 \\
\hline Housekeeping & $-0.92 * * *$ & - & 153 & 0 \\
\hline Other & $(-0.37)$ & 0.65 & 18 & 30 \\
\hline $\begin{array}{l}\text { Employed, satisfaction low with } \\
\text { job security }\end{array}$ & $0.80 * *$ & -0.01 & 70 & 45 \\
\hline $\begin{array}{l}\text { Employed, satisfaction medium } \\
\text { with job security }\end{array}$ & $0.31 *$ & $0.46^{*}$ & 368 & 359 \\
\hline $\begin{array}{l}\text { Employed, satisfaction high with } \\
\text { job security (Ref.) }\end{array}$ & 0 & 0 & 663 & 490 \\
\hline \multicolumn{5}{|l|}{ Concerns about making ends meet } \\
\hline With (great) difficulty & $0.46^{*}$ & $0.84^{* *}$ & 146 & 66 \\
\hline With some difficulty & 0.10 & $0.49 *$ & 283 & 203 \\
\hline Fairly easily (Ref.) & 0 & 0 & 614 & 392 \\
\hline (Very) easily & $-0.47 * * *$ & -0.15 & 733 & 467 \\
\hline \multicolumn{5}{|l|}{ Control variables } \\
\hline \multicolumn{5}{|l|}{ Parity } \\
\hline Childless (Ref.) & 0 & 0 & 540 & 458 \\
\hline 1 child & 0.03 & -0.05 & 340 & 227 \\
\hline 2 children & $0.51 * *$ & -0.06 & 619 & 298 \\
\hline $3+$ children & 0.12 & -0.02 & 277 & 145 \\
\hline \multicolumn{5}{|l|}{ Age } \\
\hline $18-19$ & $0.98 * *$ & $1.36 * *$ & 61 & 44 \\
\hline $20-24$ & 0.30 & $1.20 * * *$ & 194 & 118 \\
\hline $25-29$ & 0.17 & $0.75^{*}$ & 302 & 205 \\
\hline 30-34 (Ref.) & 0 & 0 & 336 & 192 \\
\hline $35-39$ & 0.13 & 0.20 & 422 & 250 \\
\hline $40-44$ & -0.03 & 0.33 & 461 & 319 \\
\hline \multicolumn{5}{|l|}{ Education } \\
\hline Low (Ref.) & 0 & 0 & 761 & 1051 \\
\hline Medium & $0.32^{*}$ & $0.42^{*}$ & 227 & 426 \\
\hline High & $0.63^{* * *}$ & $0.65^{* *}$ & 140 & 299 \\
\hline Constant & $-1.02 * * *$ & $-2.52^{* * *}$ & & \\
\hline $\mathrm{R}^{2}$ & 0.0776 & 0.1229 & & \\
\hline $\mathrm{N}$ & 1,776 & 1,128 & 1,776 & 1,128 \\
\hline
\end{tabular}

Source: Austrian GGS, partnered persons aged 18-44 


\subsection{Economic insecurity and fertility intentions}

Next, we turn to fertility intentions for the near future (Table 5). In basic models, we include employment status and satisfaction with job security as well as concerns about making ends meet as the two single explanatory variables (Models 1a, 1w, and $1 \mathrm{~m}$ ). The extended models control for parity, age, education and sex (Models $2 \mathrm{a}, 2 \mathrm{w}$, and $2 \mathrm{~m}$ ). Positive coefficients indicate a higher likelihood of intending to have a child within the next three years.

Job insecurity is associated with fertility intentions in the sense that employed persons reporting low satisfaction with job security significantly more often intended to have a child within three years (Model 1a). With the inclusion of control variables, the estimated coefficient decreases in size and statistical significance, but remains significant in the joint model including women and men (Model 2a). In gender specific basic models, employed women as well as men dissatisfied with job security intend to have a child in the near future significantly more often (Models $1 \mathrm{w}$ and $1 \mathrm{~m}$ ). When controlling for socio-demographic characteristics (Models $2 \mathrm{w}, 2 \mathrm{~m}$ ), the association is no longer statistically significant among men $(p=0.27)$, and also beyond statistical significance among women $(p=0.102)$. Although strict reference to the $p$-values in the extended models suggests to reject hypothesis $2 a-$ stating that employment insecurity discourages fertility intentions among men and encourages fertility intentions among women - we want to emphasize that this might be due to the small sample sizes for gender-specific analyses and that, especially for women, our multivariate analyses point to a positive association between low satisfaction with job security and childbearing intentions for the near future.

Men perceiving (great) difficulties in making ends meet less often intend to have a child in the near future (Model $1 \mathrm{~m}$ ); however, with the inclusion of control variables, this association is no longer significant. In the regression models for women, material insecurity measured via concerns about making ends meet is not significantly associated with fertility intentions. Nevertheless, it must be pointed out that the estimated coefficient is positive, suggesting that women perceiving economic constraints more often intended to have a child in the near future. Persisting through all models is the observation that students (i.e. those in education) markedly less often intended to have a child in the near future. Unemployed individuals also intended to have a child in the near future less often (although coefficients for this comparably small group are not statistically significant). As mentioned earlier, enrollment in education and unemployment indicate material insecurity. Overall, combining both statistically significant output and non-significant trends - which might partly be due to small sample sizes - our results support hypothesis $2 b$, stating that material insecurity discourages fertility intentions among men and to a lesser extent among women. 
Tab. 5: Estimated coefficients for intending a child within three years

\begin{tabular}{|c|c|c|c|c|c|c|}
\hline & $\begin{array}{c}\text { All } \\
\text { Model 1a }\end{array}$ & $\begin{array}{c}\text { All } \\
\text { Model 2a }\end{array}$ & $\begin{array}{l}\text { Women } \\
\text { Model 1w }\end{array}$ & $\begin{array}{l}\text { Women } \\
\text { Model 2w }\end{array}$ & $\begin{array}{c}\text { Men } \\
\text { Model } 1 \mathrm{~m}\end{array}$ & $\begin{array}{c}\text { Men } \\
\text { Model 2m }\end{array}$ \\
\hline \multicolumn{7}{|c|}{ Employment status and satisfaction with job security } \\
\hline Self-employed & 0.01 & $0.46^{*}$ & -0.06 & $0.70^{*}$ & 0.00 & 0.27 \\
\hline Unemployed & -0.16 & -0.27 & -0.26 & -0.29 & 0.16 & -0.16 \\
\hline Student & $-0.60 * *$ & $-1.21 * * *$ & -0.36 & $-1.21 * * *$ & $-1.00 * *$ & $-1.35^{* *}$ \\
\hline Leave & $0.47^{* *}$ & $0.82^{* * *}$ & $0.57 * * *$ & $0.87 * * *$ & - & - \\
\hline Housekeeping & $-0.99 * * *$ & -0.01 & $-0.87 * * *$ & 0.13 & - & - \\
\hline Other & -0.33 & $-0.76^{*}$ & -0.34 & -1.01 & -0.44 & -0.43 \\
\hline $\begin{array}{l}\text { Employed, satisfaction } \\
\text { low }\end{array}$ & $0.68 * * *$ & $0.44^{+}$ & $0.76^{* *}$ & $0.53^{a}$ & $0.67 *$ & 0.43 \\
\hline $\begin{array}{l}\text { Employed, satisfaction } \\
\text { medium }\end{array}$ & 0.03 & 0.03 & -0.03 & -0.12 & 0.05 & 0.16 \\
\hline $\begin{array}{l}\text { Employed, satisfaction } \\
\text { high (Ref.) }\end{array}$ & 0 & 0 & 0 & 0 & 0 & 0 \\
\hline \multicolumn{7}{|c|}{ Concerns about making ends meet } \\
\hline With (great) difficulty & -0.16 & 0.09 & 0.03 & 0.34 & $-0.55^{+}$ & -0.42 \\
\hline With some difficulty & -0.17 & 0.05 & -0.13 & 0.04 & -0.25 & 0.03 \\
\hline Fairly easily (Ref.) & 0 & 0 & 0 & 0 & 0 & 0 \\
\hline (Very) easily & 0.10 & 0.03 & 0.02 & -0.10 & 0.22 & 0.21 \\
\hline \multicolumn{7}{|l|}{ Control variables } \\
\hline \multicolumn{7}{|l|}{ Parity } \\
\hline Childless (Ref.) & & 0 & & 0 & & 0 \\
\hline 1 child & & $-0.33^{*}$ & & $-0.37^{*}$ & & $-0.43^{*}$ \\
\hline 2 children & & $-2.2^{* * *}$ & & $-2.40 * * *$ & & $-2.27^{* * *}$ \\
\hline $3+$ children & & $-2.31 * * *$ & & $-2.95^{* * *}$ & & $-1.71 * * *$ \\
\hline \multicolumn{7}{|l|}{ Age } \\
\hline 18-19 & & $-1.80 * * *$ & & $-1.24 * *$ & & $-2.79 * * *$ \\
\hline $20-24$ & & $-0.74 * * *$ & & $-0.46^{*}$ & & $-1.25^{* * *}$ \\
\hline $25-29$ & & 0.11 & & $0.34^{+}$ & & -0.26 \\
\hline 30-34 (Ref.) & & 0 & & 0 & & 0 \\
\hline $35-39$ & & $-0.99 * * *$ & & $-0.89 * * *$ & & $-1.12^{* * *}$ \\
\hline $40-44$ & & $-1.83^{* * *}$ & & $-2.19 * * *$ & & $-1.61 * * *$ \\
\hline \multicolumn{7}{|l|}{ Education } \\
\hline Low (Ref.) & & 0 & & 0 & & 0 \\
\hline Medium & & -0.10 & & -0.23 & & -0.01 \\
\hline High & & 0.14 & & 0.08 & & 0.17 \\
\hline \multicolumn{7}{|l|}{ Sex } \\
\hline Male (Ref.) & & 0 & & & & \\
\hline Female & & $-0.19+$ & & & & \\
\hline Constant & $-0.91 * * *$ & $0.6 * * *$ & $-1.02 * * *$ & $0.55^{*}$ & $-0.77^{* * *}$ & $0.76^{* *}$ \\
\hline $\mathrm{R}^{2}$ & 0.0178 & 0.2478 & 0.0223 & 0.2873 & 0.0172 & 0.2159 \\
\hline $\mathrm{N}$ & 2,917 & 2,917 & 1,786 & 1,786 & 1,129 & 1,129 \\
\hline
\end{tabular}

Note: Variables refer to wave 1. For the distribution of the variables see Table A1. Significance levels: $+p<0.10 ;{ }^{*} p<0.05 ;{ }^{*} p<0.01 ;{ }^{* *} p<0.001$ a: $p=0.102$

Source: Austrian GGS waves 1 and 2 


\subsection{Economic insecurity and intentional childbearing}

As indicated earlier, roughly three out of ten partnered women and men wanted to have a child within the next three years at wave 1 (Table 3). We now concentrate on this group and analyze the realization of their fertility plans four years later (Table 6). Overall, 43 percent realized their short-term fertility intentions. The basic models include employment status combined with satisfaction with job insecurity, as well as concerns about making ends meet (Models $1 \mathrm{a}, 1 \mathrm{w}, 1 \mathrm{~m}$ ), the extended models additionally control for socio-demographic characteristics (parity, age, education, sex; Models 2a, 2w, 2m).

Employment insecurity is related with the realization of short-term fertility intentions: Employed persons with a low satisfaction with their job security realize their intentions more often compared to those who were highly satisfied with their job security (Model 1a and 2a). Gender specific analyses reveal that the estimated coefficients are positive for both women and men, but not significantly different from zero, which might partly be due to the small sample size (469 women and 362 men intending to have a child at wave 1 and observed at wave 2; among them 30 women and 20 men were employed at wave 1 and reported low satisfaction with job security). Accordingly, we have to reject hypothesis $3 a$, which states that male employment insecurity decreases the likelihood of the intention to have a child to be realized. For women, positive, albeit statistically insignificant, coefficients hint at the hypothesized link between female employment insecurity and intention realization.

Material insecurity is associated with intentional childbearing: Individuals who intended to have a child in wave 1 and who at the same time reported (great) difficulties in making ends meet, realized their fertility intentions less often compared to those who made ends meet fairly easily. The estimated coefficients are statistically significant in the joint models including both sexes (Models 1a and 2a). In the gender-specific analyses (Models $2 \mathrm{w}$ and $2 \mathrm{~m}$ ), the estimated coefficients are negative for women and men (-0.63 and -0.97 respectively) and their size indicates a stronger effect among men than women. Nevertheless, they fail statistical significance, which might again be due to the small sample sizes. Overall, we find evidence to support hypothesis $3 \mathrm{~b}$ that male material insecurity decreases the likelihood of realizing short-term fertility intentions and that for females this association is weaker. Regarding our control variables, age is particularly influential. 
Tab. 6: Estimated coefficients for realization of short-term fertility intentions

\begin{tabular}{|c|c|c|c|c|c|c|}
\hline & $\begin{array}{c}\text { All } \\
\text { Model 1a }\end{array}$ & $\begin{array}{c}\text { All } \\
\text { Model 2a }\end{array}$ & $\begin{array}{l}\text { Women } \\
\text { Model 1w }\end{array}$ & $\begin{array}{l}\text { Women } \\
\text { Model 2w }\end{array}$ & $\begin{array}{c}\text { Men } \\
\text { Model 1m }\end{array}$ & $\begin{array}{c}\text { Men } \\
\text { Model 2m }\end{array}$ \\
\hline \multicolumn{7}{|c|}{ Employment status and satisfaction with job security } \\
\hline Self-employed & 0.18 & 0.40 & -0.17 & 0.16 & 0.44 & 0.53 \\
\hline Unemployed & $0.85^{+}$ & $0.87^{+}$ & 0.81 & 1.03 & 0.96 & 1.00 \\
\hline Student & -0.33 & -0.56 & -0.00 & -0.26 & -1.18 & -1.34 \\
\hline Leave & $1.05^{* * *}$ & $0.74^{*}$ & $1.02^{* * *}$ & $0.88^{*}$ & - & - \\
\hline Housekeeping & 0.18 & 0.22 & 0.15 & 0.56 & - & - \\
\hline Other & -0.37 & -0.68 & - & - & 0.40 & 0.35 \\
\hline $\begin{array}{l}\text { Employed, satisfaction } \\
\text { low }\end{array}$ & $0.55^{+}$ & $0.56^{+}$ & 0.49 & 0.68 & 0.68 & 0.53 \\
\hline $\begin{array}{l}\text { Employed, satisfaction } \\
\text { medium }\end{array}$ & -0.08 & -0.10 & 0.11 & 0.14 & -0.22 & -0.30 \\
\hline $\begin{array}{l}\text { Employed, satisfaction } \\
\text { high (Ref.) }\end{array}$ & 0 & 0 & 0 & 0 & 0 & 0 \\
\hline \multicolumn{7}{|c|}{ Concerns about making ends meet } \\
\hline With (great) difficulty & $-0.77^{*}$ & $-0.79 *$ & -0.58 & -0.63 & $-1.17^{+}$ & -0.97 \\
\hline With some difficulty & -0.32 & -0.27 & -0.09 & -0.07 & $-0.61+$ & -0.58 \\
\hline Fairly easily (Ref.) & 0 & 0 & 0 & 0 & 0 & 0 \\
\hline (Very) easily & 0.21 & 0.24 & 0.28 & 0.23 & 0.15 & 0.24 \\
\hline \multicolumn{7}{|l|}{ Control variables } \\
\hline \multicolumn{7}{|l|}{ Parity } \\
\hline Childless (Ref.) & & 0 & & 0 & & 0 \\
\hline 1 child & & 0.32 & & 0.10 & & $0.53^{+}$ \\
\hline 2 children & & 0.34 & & 0.03 & & $0.79^{+}$ \\
\hline $3+$ children & & 0.15 & & 0.43 & & 0.06 \\
\hline \multicolumn{7}{|l|}{ Age } \\
\hline 18-19 & & -0.06 & & -0.28 & & -0.08 \\
\hline $20-24$ & & 0.02 & & 0.12 & & -0.23 \\
\hline $25-29$ & & -0.10 & & 0.12 & & -0.40 \\
\hline 30-34 (Ref.) & & 0 & & 0 & & 0 \\
\hline $35-39$ & & $-1.10 * * *$ & & $-1.33^{* * *}$ & & $-0.94^{* *}$ \\
\hline $40-44$ & & $-1.94 * * *$ & & $-3.67^{* * *}$ & & $-1.70^{* * *}$ \\
\hline \multicolumn{7}{|l|}{ Education } \\
\hline Low (Ref.) & & 0 & & 0 & & 0 \\
\hline Medium & & -0.09 & & -0.04 & & -0.21 \\
\hline High & & 0.27 & & 0.32 & & 0.26 \\
\hline \multicolumn{7}{|l|}{ Sex } \\
\hline Male (Ref.) & & 0 & & & & \\
\hline Female & & -0.07 & & & & \\
\hline Constant & -0.15 & 0.08 & -0.21 & -0.07 & -0.09 & 0.20 \\
\hline $\mathrm{R}^{2}$ & 0.0326 & 0.0864 & 0.0358 & 0.1198 & 0.0330 & 0.0845 \\
\hline $\mathrm{N}$ & 836 & 836 & 469 & 469 & 362 & 362 \\
\hline
\end{tabular}

Note: Variables refer to wave 1. For the distribution of the variables see Table A2.

Significance levels: $+p<0.10 ;{ }^{*} p<0.05 ;{ }^{* *} p<0.01 ;{ }^{* *} p<0.001$

Source: Austrian GGS waves 1 and 2 


\section{Summary and discussion}

This study has addressed the question of when paid work matters in reproductive decisions, by testing how objective economic conditions and the subjective perception of them are related to the salience of work in childbearing intentions, to the construction of childbearing intentions, and subsequent behavior in the Austrian context. Results on the relationship between employment and material insecurity and the importance of paid work for developing childbearing intentions indicate that paid work does indeed matter. The cognitive evaluation of how important work is in developing childbearing intentions is subject to the restraining effect of a low satisfaction with job security. This inference is valid for women and men. Moderate and high levels of dissatisfaction with job security make employed women more likely to value paid work as important in the decision to have a child. This also holds true for men reporting a medium level of dissatisfaction with their job security. The cognitive evaluation of how important work is in reproductive decisions is subject to greater perceived material insecurity among men than women. For individuals concerned about making ends meet, paid work is important for the construction of childbearing plans.

These results provide empirical evidence for Goszczynska et al.'s (1991) argument that work and related benefits become salient when they are insecure. Because respondents became more aware of material and other work-related resources that they have but are likely to lose (involuntarily) in the near future, they assign greater relevance to paid work in the childbearing decision. First, under material insecurity, income from labor is threatened and this is detrimental for a person's breadwinning capacity, especially for men, when having children. These results corroborate findings for (West) Germany by Andersson et al. (2009) and for Switzerland by Hanappi et al. (2016), where women usually reduce their employment activities after childbirth, and thus a female income is not necessarily a pre-requisite for having children. Second, our results hint at the idea that childbearing might be an attractive option for individuals who report a low satisfaction with job security. The higher likelihood of employed women who are dissatisfied with job security to intend to have a child in the near future reflects the emotional benefits of motherhood prevalent in our study context. Third, once people intend to have a child in the near future, those with a low level of satisfaction with job security are more likely to realize their intentions, which supports Friedman et al.'s (1994) uncertainty reduction argument.

The above findings are also an extension of the pioneering work by Philipov (2009), which rested on the argument that work could in some cases be more important than, and thus compete with, having children. The results here show how employment status and level of satisfaction with job insecurity shape the cognitive evaluation of paid work as a factor in reproductive decisions in the first place. It suggests that the perception that one's job might be lost and financial constraints shape individuals' awareness of the work-related benefits that might be lost when having children; thus insecurities contribute by framing evaluations of work as a factor in reproductive decisions. 
Results on the interplay of material insecurity and intentional childbearing reveal that work is relevant for realizing short-term fertility. These results corroborate findings that actual unemployment and perceived economic uncertainty impact the transition to parenthood (Andersson 2000; Blossfeld et al. 2005; Gebel/Giesecke 2009; Kreyenfeld 2009).

Some limitations of this study should be mentioned. The empirical analysis on intention realization is based on short-term fertility intentions. It thus remains unclear whether those who did not realize their intentions in the foreseen time frame achieved their fertility goals later on. We are also aware that having only two waves available in our dataset may not be sufficient to grasp variations in individuals' intentions in the very short run; nor does it allow an insight into sudden intention changes due to the occurrence of critical events in work and family life (e.g. job changes or family re-composition). We are aware that the sample reporting material insecurity is small, which limits representativity. Also, there might be a causal relationship between the importance of work and future childbearing pointing in the other direction: We argued earlier that paid work can be important because current insecure employment conditions are perceived as discouraging childbearing plans. At the same time, a future or ongoing occupational career can be hampered by childbearing. Finally, the influence of the satisfaction on the employment condition on fertility intentions may be biased because of the possible presence of unobserved variables that have an impact on both. For instance, intrinsically optimistic individuals may be inclined to answer that they are satisfied and intend having a(nother) child - thus creating an artificial association between employment satisfaction and fertility intentions.

Despite such limitations, our results have a number of implications for understanding the complex links between work and fertility. Although few differences in the effect of employment status and insecurity on intention realization where found by gender, major gender differences in the association of employment status and work salience were found. More precisely, women currently working in insecure employment conditions anticipate the potential risks associated with a long absence from work after childbirth. Overall, we show that if reproductive decisions depend on employment and material insecurity, they also vary within groups reporting such insecurities, according to people's labor market prospects and family and career aspirations. Our findings stem from a context in which, despite increased feelings of economic insecurity, unemployment and labor market uncertainty are relatively low compared to the European average. In contexts with higher unemployment and less strict employment protection legislation, economic insecurities may have a larger impact in determining fertility intentions and their realization. Therefore, the knowledge of what differentiates people who consider paid work as important for fertility and those who do not, might expand our understanding of why work prevents some groups from realizing their intentions and not others. It is preferable to use this alternative contrast when the state of job insecurity is included in models for fertility analyses. 


\section{Acknowledgements}

We wish to thank Jennifer Johnson-Hanks, Caroline Berghammer and two anonymous reviewers as well as the editor for their valuable comments on earlier versions of the paper. This study was conducted with the financial support of the Austrian Academy of Sciences under the grant number 11713 within the Austrian Program for Advanced Research and Technology and within the project "Running against the clock", financed by the Austrian Research Foundation (FWF28071).

\section{References}

Adsera, Alicia 2011a: The interplay of employment uncertainty and education in explaining second births in Europe. In: Demographic Research 25,16: 513-544 [doi: 10.4054/ DemRes.2011.25.16].

Adsera, Alicia 2011b: Where are the babies? Labor market conditions and fertility in Europe. In: European Journal of Population 27,1: 1-32 [doi: 10.1007/s10680-010-9222-x].

Ahn, Namkee; Mira, Pedro 2002: A note on the changing relationship between fertility and female employment rates in developed countries. In: Journal of Population Economics 15,4: 667-682 [doi: 10.1007/s001480100078].

Ajzen, Icek 1991: The theory of planned behavior. In: Organizational Behavior and Human Decision Processes 50,2: 179-211 [doi: 10.1016/0749-5978(91)90020-T].

Ajzen, Icek; Fishbein, Martin 2005: The influence of attitudes on behavior. In: Albarracín, Dolores; Johnson, Blair T.; Zanna, Mark P. (Eds.): The handbook of attitudes. Mahwah. New Jersey/London: Lawrence Erlbaum Associates: 173-221.

Ajzen, Icek; Klobas, Jane 2013: Fertility intentions: An approach based on the Theory of Planned Behavior. In: Demographic Research 29,8: 203-232 [doi: 10.4054/DemRes.2013.29.8].

Aldrich, John H.; Nelson, Forrest D. 1986: Logit and probit models for multivariate analysis with qualitative dependent variables. In: New Tools for Social Scientists: Advances and Applications in Research Methods: 115-155.

Anderson, Christopher J.; Pontusson, Jonas 2007: Workers, worries and welfare states: Social protection and job insecurity in 15 OECD countries. In: European Journal of Political Research 46,2: 211-235 [doi: 10.1111/j.1475-6765.2007.00692.x].

Andersson, Gunnar 2000: The impact of labour-force participation on childbearing behaviour: pro-cyclical fertility in Sweden during the 1980s and the 1990s. In: European Journal of Population 16,4: 293-333.

Andersson, Gunnar et al. 2009: Cohort fertility patterns in the Nordic countries. In: Demographic Research 20,14: 313-352 [doi: 10.4054/DemRes.2009.20.14].

Barber, Jennifer S. 2001: Ideational influences on the transition to parenthood: Attitudes toward childbearing and competing alternatives. In: Social Psychology Quarterly 64,2: 101-127.

Barber, Jennifer S.; Axinn, William G. 2005: How do attitudes shape childbearing in the United States. In: Booth, Alan; Crouter, Ann (Eds.): The new population problem: Why families in developed countries are shrinking and what it means. Mahwah/New Jersey/ London: Lawrence Erlbaum Associates Publishers: 59-92.

Becker, Gary 1981: A Treatise on the family. Cambridge: Harvard University Press. 
Begall, Katia; Mills, Melinda 2011: The impact of subjective work control, job strain and work-family conflict on fertility intentions: A European comparison. In: European Journal of Population 27,4: 433-456 [doi: 10.1007/s10680-011-9244-z].

Berghammer, Caroline 2014: The return of the male breadwinner model? Educational effects on parents' work arrangements in Austria, 1980-2009. In: Work, Employment and Society 28,4: 611-623 [doi: 10.1177/0950017013500115].

Bernardi, Fabrizio 2001: The employment behaviour of married women in Italy. In: Careers of couples in contemporary societies: 121-145.

Bernardi, Laura; Klärner, Andreas; von der Lippe, Holger 2008: Job insecurity and the timing of parenthood: A comparison between Eastern and Western Germany. In: European Journal of Population 24,3: 287-313 [doi: 10.1007/s10680-007-9127-5].

Berrington, Ann; Pattaro, Serena 2014: Educational differences in fertility desires, intentions and behaviour: A life course perspective. In: Advances in Life Course Research 21: 10-27 [doi: 10.1016/j.alcr.2013.12.003].

Billari, Francesco; Philipov, Dimiter; Testa, Maria Rita 2009: Attitudes, norms and perceived behavioural control: Explaining fertility intentions in Bulgaria. In: European Journal of Population 25: 439-465.

Blossfeld, Hans-Peter; Hofmeister, Heather 2007: Globalization, uncertainty and women's careers: An international comparison. Chelteham, UK /Northampton, MA: Edward Elgar Publishing.

Blossfeld, Hans-Peter et al. 2005: Globalization, uncertainty and youth society. London/ New York: Routledge.

BMFJ (Bundesministerium für Familien und Jugend) 2016: Kindergeldkonto kommt ab 1.3.2017 [Child benefit account starts on March 1, 2017] [https://www.bmfj.gv.at/ministerin/Aktuelles/Themen/Kindergeldkonto-Neu.html, 03.11.2017].

Bonoli, Giuliano 2008: The impact of social policy on fertility: Evidence from Switzerland. In: Journal of European Social Policy 18,1: 64-77 [doi: 10.1177/0958928707081074].

Brady, David 2003: Rethinking the sociological measurement of poverty. In: Social Forces 81,3: 715-752 [doi: 10.1353/sof.2003.0025].

Buber, Isabel/a 2010: Parity-specific weights for the Austrian Generations and Gender Survey. VID Working Paper 4/2010: Vienna Institute of Demography.

Buber-Ennser, Isabel/a 2014: Attrition in the Austrian Generations and Gender Survey: Is there a bias by fertility-relevant aspects? In: Demographic Research 31,16: 459-496 [doi: 10.4054/DemRes.2014.31.16].

Buber-Ennser, Isabella 2015: Childrearing in Austria: Work and family roles. In: Journal of Research in Gender Studies 5,2: 121-146.

Buber, Isabella; Neuwirth, Norbert 2009: Familienentwicklung in Österreich. Erste Ergebnisse des "Generations and Gender Survey (GGS)" 2008/09 [Family development in Austria. First results of the "Generations and Gender Survey (GGS)" 2008/09]. Vienna: Vienna Institute of Demography.

Buber-Ennser, Isabella; Fliegenschnee, Katrin 2013: Being ready for a child. A mixedmethods investigation of fertility intentions. In: Family Science 4,1: 139-147 [doi: 10.1080/19424620.2013.871739].

Butz, William P.; Ward, Michael P. 1979: The emergence of countercyclical U.S. fertility. In: The American Economic Review 69,3: 318-328.

Castel, Robert; Dörre, Klaus 2009: Prekarität, Abstieg, Ausgrenzung. Die soziale Frage am Beginn des 21. Jahrhunderts. Frankfurt/New York: Campus Verlag. 
Cherlin, Andrew et al. 2013: The Effects of the Great Recession on Family Structure and Fertility. In: The ANNALS of the American Academy of Political and Social Science 650,1: 214-231 [doi: 10.1177/0002716213500643].

Comolli, Chiara Ludovica 2017: The fertility response to the Great Recession in Europe and the United States: Structural economic conditions and perceived economic uncertainty. In: Demographic Research 36,51: 1549-1600 [doi: 10.4054/DemRes.2017.36.51].

Correll, Shelley J.; Benard, Stephe.; Paik, In 2007: Getting a Job: Is there a motherhood penalty? In: American Journal of Sociology 112,5: 1297-1339 [doi: 10.1086/511799].

Danziger, Sheldon; Chavez, Koji; Cumberworth, Erin 2012: Poverty and the great recession. In: Stanford, CA: Stanford Center on Poverty and Inequality [https://web. stanford.edu/group/recessiontrends/cgi-bin/web/sites/all/themes/barron/pdf/Poverty_fact_sheet.pdf, 01.03.2015].

De Cuyper, Nele; De Witte, Hans 2006: The impact of job insecurity and contract type on attitudes, well-being and behavioural reports: a psychological contract perspective. In: Journal of Occupational and Organizational Psychology 79,3: 395-409 [doi: 10.1348/096317905X53660].

De Cuyper, Nele; Isaksson, Kerstin 2017: Employment contracts and well-being among European workers. Routledge.

Del Boca, Daniela; Sauer, Robert M. 2009: Life cycle employment and fertility across institutional environments. In: European Economic Review 53,3: 274-292 [doi: 10.1016/j. euroecorev.2008.06.001].

Del Bono, Emilia; Weber, Andrea; Winter-Ebmer, Rudolf 2012: Clash of career and family: Fertility decisions after job displacement. In: Journal of the European Economic Association 10,4: 659-683 [doi: 10.1111/j.1542-4774.2012.01074.x].

Del Bono, Emilia; Weber, Andrea; Winter-Ebmer, Rudolf 2014: Fertility and economic instability: The role of unemployment and job displacement. In: Journal of Population Economics 28,2: 463-478 [doi: 10.1007/s00148-014-0531-y].

Dommermuth, Lars; Klobas, Jane; Lappegård, Trude 2011: Now or later? The Theory of Planned Behavior and timing of fertility intentions In: Advances in Life Course Research 16: 42-53 [doi: 10.1016/j.alcr.2011.01.002].

Dommermuth, Lars; Klobas, Jane; Lappegård, Trude 2015: Realization of fertility intentions by different time frames. In: Advances in Life Course Research 24: 34-46 [doi: 10.1016/j.alcr.2015.02.001].

Eichmann, Hubert; Saupe, Bernhard 2014: Überblick über Arbeitsbedingungen in Österreich: Follow-up-Studie. Sozialpolitische Studienreihe 15. Vienna: ÖGB-Verlag.

Esping-Andersen, Gosta 2009: Incomplete revolution: Adapting welfare states to women's new roles. Cambridge: Polity Press.

Esser, Ingrid; Olsen, Karen M. 2011: Perceived job quality: Autonomy and job security within a multi-level framework. In: European Sociological Review 28,4: 443-454 [doi: 10.1093/esr/jcr009].

EUROSTAT 2017: Part-time Employment Rate [http://ec.europa.eu/eurostat/tgm/table. do?tab=table\&init=1\&language $=$ en\&pcode $=$ tesem100\&plugin =1, 13.11.2017] .

Festl, Eva; Lutz, Hedwig; Schratzenstaller, Margit 2010: Mögliche Ansätze zur Unterstützung von Familien [Possible approaches to support families]. Vienna: WIFO Austrian Institute of Economic Research.

Friedman, Debra; Hechter, Michael; Kanazawa, Satoshi 1994: A theory of the value of children. In: Demography 31,3: 375-401 [doi: 10.2307/2061749]. 
Gebel, Michael; Giesecke, Johannes 2009: Ökonomische Unsicherheit und Fertilität. Die Wirkung von Beschäftigungsunsicherheit und Arbeitslosigkeit auf die Familiengründung in Ost- und Westdeutschland [Economic insecurity and fertility. The effects of job insecurity and unemployment on family formation in East and West Germany]. In: Zeitschrift für Soziologie 38,5: 399-417 [doi: 10.1515/zfsoz-2009-0504].

Goldstein, Joshua et al. 2013: Fertility reactions to the "Great Recession" in Europe: Recent evidence from order-specific data. In: Demographic Research 29,4: 85-104 [doi: 10.4054/DemRes.2013.29.4].

Goldstein, Joshua; Lutz, Wolfgang; Testa, Maria Rita 2003: The emergence of sub-replacement family size ideals in Europe. In: Population Research and Policy Review 22,5-6: 479-496.

Golsch, Katrin 2003: Employment flexibility in Spain and its impact on transitions to adulthood. In: Work, Employment \& Society 17,4: 691-718 [doi: 10.1177/0950017003174005].

Goszczynska, Maryla; Tyszka, Tadeusz; Slovic, Paul 1991: Risk perception in Poland: A comparison with three other countries. In: Journal of Behavioral Decision Making 4,3: 179-193 [doi: 10.1002/bdm.3960040305].

Greenhaus, Jeffrey H. et al. 1989: Sources of work-family conflict among two-career couples. In: Journal of Vocational Behavior 34,2: 133-153 [doi: 10.1016/00018791(89)90010-9].

Grunow, Daniela; Hofmeister, Heather; Buchholz, Sandra 2006: Late 20th-century persistence and decline of the female homemaker in Germany and the United States. In: International Sociology 21,1: 101-131 [doi: 10.1177/0268580906059294].

Gustafsson, Siv 2001: Optimal age at motherhood. Theoretical and empirical considerations on postponement of maternity in Europe. In: Journal of Population Economics 14,2: 225-247 [doi: 10.1007/s001480000051].

Hakim, Catherine 2003: A new approach to explaining fertility patterns: Preference theory. In: Population and Development Review 29,3: 349-374 [doi: 10.1111/j.17284457.2003.00349.x].

Hanappi, Doris et al. 2017: Changes in employment uncertainty and the fertility intention-behavior link: An analysis based on the Swiss household panel data. In: European Journal of Population 33,3: 381-407 [doi: 10.1007/s10680-016-9408-y].

Hanappi, Doris; Ryse, Valérie-Anne; Bernardi, Laura 2016: The role of attitudes towards maternal employment in the relationship between job quality and fertility intentions. In: Journal of Research in Gender Studies 6,1: 192-219.

Jahoda, Marie 1982: Employment and unemployment: A social-psychological analysis. Cambridge, UK: Cambridge University Press.

Jalovaara, Marika et al. 2017: Education, gender, and cohort fertility in the Nordic countries. In: Stockholm Research Reports in Demography 6. Stockholm: Stockholm University, Department of Sociology.

Johnson-Hanks, Jennifer A. et al. 2012: Understanding family change and variation: Toward a Theory of Conjunctural Action. New York: Springer [doi: 10.1007/978-94007-1945-3].

Korpi, Walter 2000: Faces of inequality: Gender, class, and patterns of inequalities in different types of welfare states. In: Social Politics: International Studies in Gender, State \& Society 7,2: 127-191 [doi: 10.1093/sp/7.2.127].

Kravdal, Øystein 2002: The impact of individual and aggregate unemployment on fertility in Norway. In: Demographic Research 6,10: 263-294 [doi: 10.4054/DemRes.2002.6.10]. 
Kravdal, Øystein; Rindfuss, Ronald R. 2008: Changing relationships between education and fertility: A study of women and men born 1940 to 1964. In: American Sociological Review 73: 854-873 [doi: 10.1177/000312240807300508].

Kreimer, Margareta 2011: Familienpolitische Maßnahmen in Österreich: Paradigmenwechsel auf halbem Weg [Family policy measures in Austria: Paradigm shift half way between]. In: Kreimer, Margareta; Sturn, Richard; Dujmovits, Rudolf (Eds.): Paradigmenwechsel in der Familienpolitik [Paradigm shift in family policy]. Wiesbaden: Springer: 83-110 [doi: 10.1007/978-3-531-93360-3].

Kreyenfeld, Michaela 2009: Uncertainties in female employment careers and the postponement of parenthood in Germany. In: European Sociological Review 26,3: 351-366 [doi: 10.1093/esr/jcp026].

Kreyenfeld, Michaela 2015: Economic uncertainty and fertility. In: KZfSS Kölner Zeitschrift für Soziologie und Sozialpsychologie 67,1: 59-80 [doi: 10.1007/s11577-0150325-6].

Kreyenfeld, Michaela; Andersson, Gunnar; Pailhé, Ariane 2012: Economic uncertainty and family dynamics in Europe: Introduction. In: Demographic Research 27,28: 835852 [doi: 10.4054/DemRes.2012.27.28].

Kreyenfeld, Michaela; Andersson, Gunnar 2014: Socioeconomic differences in the unemployment and fertility nexus: Evidence from Denmark and Germany. In: Advances in Life Course Research 21: 59-73 [doi: 10.1016/j.alcr.2014.01.007].

Kuhnt, Anne-Kristin; Trappe, Heike 2016: Channels of social influence on the realization of short-term fertility intentions in Germany. In: Advances in Life Course Research 27: 16-29 [doi: 10.1016/j.alcr.2015.10.002].

Lalive, Rafael; Zweimüller, Josef 2009: How does parental leave affect fertility and return to work? Evidence from two natural experiments. In: The Quarterly Journal of Economics 124,3: 1363-1402 [doi: 10.1162/qjec.2009.124.3.1363].

Lent, Robert W.; Brown, Steve D. 2008: Social cognitive career theory and subjective well-being in the context of work. In: Journal of Career Assessment 16,1: 6-21 [doi: 10.1177/1069072707305769].

Léridon, Henri 1995: Les enfants du désir. Paris: Julliard.

Martín García, Teresa 2010: The impact of occupational sex-composition on women's fertility in Spain. In: European Societies 12,1: 113-133 [doi: 10.1080/14616690802474366].

Matysiak, Anna; Vignoli, Daniele 2008: Fertility and women's employment: A metaanalysis. In: European Journal of Population 24,4: 363-384 [doi: 10.1007/s10680-0079146-2].

Mencarini, Letizia; Vignoli, Daniele; Gottard, Anna 2015: Fertility intentions and outcomes: Implementing the theory of planned behavior with graphical models. In: Advances in Life Course Research 23: 14-28 [doi: 10.1016/j.alcr.2014.12.004].

Miller, Warren B.; Pasta, David J. 1995: Behavioral intentions: Which ones predict fertility behavior in married couples? In: Journal of Applied Social Psychology 25,6: 530 555 [doi: 10.1111/j.1559-1816.1995.tb01766.x].

Miller, Warren B.; Severy, Lawrence J.; Pasta, David J. 2004: A framework for modelling fertility motivation in couples. In: Population Studies 58,2: 193-205 [doi: 10.1080/0032472042000213712].

Modena, Francesca; Sabatini, Fabio 2012: I would if I could: Precarious employment and childbearing intentions in Italy. In: Review of Economics of the Household 10,1: 77-97 [doi: 10.1007/s11150-010-9117-y]. 
Moen, Phyllis 1985: The two-provider family: Problems and potentials. In: Olson, David H.; Miller, Brent $C$. (Eds.): Family studies review yearbook: Volume 3. Beverly Hills: Sage Publications:

Moen, Phyllis; Kelly, Erin; Huang, Qinlei 2008: Work, family and life-course fit: Does control over work time matter? In: Journal of Vocational Behavior 73,3: 414-425 [doi: 10.1016/j.jvb.2008.08.002].

Morgan, S. Philip; Rackin, Heather 2010: The correspondence between fertility intentions and behavior in the United States. In: Population and Development Review 36,1: 91-118 [doi: 10.1111/j.1728-4457.2010.00319.x].

Mynarska, Monika 2010: Deadline for parenthood: fertility postponement and age norms in Poland. In: European Journal of Population 26,3: 351-373 [doi: 10.1007/s10680-0099194-x].

Neyer, Gerda; Hoem, Jan M. 2008: Education and permanent childlessness: Austria vs. Sweden. A research note. In: Surkyn, Johan; Deboosere, Patrick; van Bavel, Jan (Eds.): Demographic challenges for the 21st century. Brussels: Brussels University Press: 91-112.

Neyer, Gerda; Lappegård, Trude; Vignoli, Daniele 2013: Gender equality and fertility: Which equality matters? In: European Journal of Population 29,3: 245-272 [doi: 10.1007/s10680-013-9292-7].

Nomaguchi, Kei M. 2012: Parenthood and psychological well-being: Clarifying the role of child age and parent-child relationship quality. In: Social Science Research 41,2: 489-498 [doi: 10.1016/j.ssresearch.2011.08.001].

OECD 2015: OECD economic surveys: Austria/Paris: OECD Publishing [doi: 10.1787/ eco_surveys-aut-2015-en].

OECD 2017: Labor Force Statistics by Sex and Age [https://stats.oecd.org/lndex. aspx?DataSetCode=LFS_SEXAGE_I_R, 13.11.2017].

Oesch, Daniel; Lipps, Oliver 2013: Does unemployment hurt less if there is more of it around? A panel analysis of life satisfaction in Germany and Switzerland. In: European Sociological Review 29,5: 955-967 [doi: 10.1093/esr/jcs071].

Pailhé, Ariane; Solaz, Anne 2012: The influence of employment uncertainty on childbearing in France: A tempo or quantum effect? In: Demographic Research 26: 1-40 [doi: 10.4054/DemRes.2012.26.1].

Philipov, Dimiter 2009: The effect of competing intentions and behaviour on short-term childbearing intentions and subsequent childbearing. In: European Journal of Population 25,4: 525-548 [doi: 10.1007/s10680-009-9197-7].

Philipov, Dimiter; Bernardi, Laura 2011: Concepts and operationalization of reproductive decisions. Implementations in Austria, Germany and Switzerland. In: Comparative Population Studies - Zeitschrift für Bevölkerungswissenschaft 36,2-3: 495-530 [doi: 10.4232/10.CPoS-2011-14en].

Prskawetz, Alexia et al. 2008: Austria: Persistent low fertility since the mid-1980s. In: Demographic Research 19,12: 293-360 [doi: 10.4054/DemRes.2008.19.12].

Quesnel-Vallée, Amélie; Morgan, S. Philip 2003: Missing the target? Correspondence of fertility intentions and behavior in the U.S. In: Population Research and Policy Review 22: 497-525 [doi: 10.1023/B:POPU.0000021074.33415.c1].

Rindfuss, Ronald R.; Morgan, S. Philip; Offutt, Kate 1996: Education and the changing age pattern of American fertility: 1963-1989. In: Demography 33,3: 277-290 [doi: $10.2307 / 2061761]$. 
Rindfuss, Ronald R.; Sweet, James A. 2013: Postwar fertility trends and differentials in the United States. Elsevier.

Rondinelli, Concetta; Aassve, Arnstein; Billari, Francesco C. 2006: Income and childbearing decisions: Evidence from Italy. ISER Working Paper Series.

Rossier, Clémentine; Bernardi, Laura 2009: Social interaction effects on fertility: Intentions and behaviors. In: European Journal of Population 25,4: 467-485 [doi: 10.1007/ s10680-009-9203-0].

Schmitt, Christian 2008: Gender-specific effects of unemployment on family formation: a cross-national perspective. In: Discussion Papers 841. Deutsches Institut für Wirtschaftsforschung.

Schmitt, Christian 2012: A cross-national perspective on unemployment and first birth. In: European Journal of Population 28,3: 303-305 [doi: 10.1007/s10680-012-9262-5].

Schneider, Danie/ 2015: The great recession, fertility, and uncertainty: Evidence from the united states. In: Journal of Marriage and Family 77,5: 1144-1156 [doi: 10.1111/ jomf.12212].

Selenko, Eva; Batinic, Bernad 2013: Job insecurity and the benefits of work. In: European Journal of Work and Organizational Psychology 22,6: 725-736 [doi: 10.1080/1359432X.2012.703376].

Sen, Amartya 2001: Development as freedom. Oxford Paperbacks.

Sobotka, Tomáš 2011: Fertility in Austria, Germany and Switzerland: Is there a common pattern? In: Comparative Population Studies - Zeitschrift für Bevölkerungswissenschaft 36,2-3: 263-304 [doi: 10.4232/10.CPoS-2011-11en].

Sobotka, Tomáš; Skirbekk, Vegard; Philipov, Dimiter 2011: Economic recession and fertility in the developed world. In: Population and Development Review 37,2: 267-306 [doi: 10.1111/j.1728-4457.2011.00411.x].

Sobotka, Tomás; Testa, Maria Rita 2008: Attitudes and intentions toward childlessness in Europe. In: Höhn, Charlotte; Avramov, Dragana; Kotowska, Irena E. (Eds.): People, population change and policies: Lessons from the Population Policy Acceptance Study. Berlin: Springer: 177-211.

Spéder, Zsolt; Kapitány, Balázs 2009: How are time-dependent childbearing intentions realized? Realization, postponement, abandonment, bridging forward. In: European Journal of Population 25: 503-523 [doi: 10.1007/s10680-009-9189-7].

Spéder, Zsolt; Kapitány, Balázs 2015: Influences on the link between fertility intentions and behavioural outcomes. In: Philipov, Dimiter; Liefbroer, Aart C.; Klobas, Jane E. (Eds.): Reproductive decision-making in a macro-micro perspective. Springer: 79-112 [doi: 10.1007/978-94-017-9401-5].

Statistik Austria 2009: Generations and Gender Survey. Familienentwicklung in Österreich. Welle 1 - Generationen und Geschlechterrollen. Endbericht [Generations and Gender Survey. Family development in Austria. Wave 1 -generations and gender roles]. Vienna: Statistik Austria.

Statistik Austria 2016: Erwerbstätige und unselbständig Erwerbstätige nach Vollzeit/ Teilzeit und Geschlecht seit 1994 [http://www.statistik.at/web de/statistiken/menschen_und_gesellschaft/soziales/gender-statistik/erwerbstaetigkeit/043906.html, 13.11.2017].

Testa, Maria Rita; Cavalli, Laura; Rosina, Alessandro 2011: Couples' childbearing behaviour in Italy: Which of the partners is leading it? In: Vienna Yearbook of Population Research 9: 157-178. 
Testa, Maria Rita; Gietel-Basten, Stuart 2014: Certainty of meeting fertility intentions declines in Europe during the "Great Recession". In: Demographic Research 31,23: 687-734 [doi: 10.4054/DemRes.2014.31.23].

Thévenon, Olivier 2010: Does fertility respond to work and family-life reconciliation policies in France? In: Noriyuki, Takayama; Werding, Martin (Eds.): Fertility and public policy: How to reverse the trend of declining birth rates. Cambridge MA/London UK: MIT Press: 231-261

Treas, Judith 2010: The great American recession: Sociological insights on blame and pain. In: Sociological Perspectives 53,1: 3-17 [doi: 10.1525/sop.2010.53.1.3].

Vignoli, Daniele; Drefahl, Sven; De Santis, Gustavo 2012: Whose job instability affects the likelihood of becoming a parent in Italy? A tale of two partners. In: Demographic Research 26,2: 41-62 [doi: 10.4054/DemRes.2012.26.2].

Wernhart, Georg; Neuwirth, Norbert 2007: Geschlechterrollenwandel und Familienwerte (1988-2002). Österreich im europäischen Vergleich. Ergebnisse auf Basis des ISSP 1998, 2002 [Changes in gender roles and family values (1988-2002). Austria in a European comparison. Results based on the ISSP 1998, 2002]. ÖIF Working Paper 54, Vienna: Österreichisches Institut für Familienforschung/Austrian Institute for Family Research.

Whelpton, Pascal Kidder; Campbell, Arthur A.; Patterson, John E. 2015: Fertility and family planning in the United States. Princeton: Princeton University Press.

Doris Hanappi $(\bowtie)$. University of California. Berkeley, CA, United States USA. Research Fellow of the Austrian Academy of Sciences (ÖAW).

E-mail: doris.hanappi@gmail.com

URL: https://www.researchgate.net/profile/Doris_Hanappi http://dorishanappi.info

Isabella Buber-Ennser. Wittgenstein Centre (IIASA, VID/ÖAW, WU). Vienna Institute of Demography/Austrian Academy of Sciences. Vienna, Austria.

E-mail: isabella.buber@oeaw.ac.at

URL: http://www.wittgensteincentre.org/en/staff/member/buber-ennser.htm https://www.oeaw.ac.at/en/vid/people/staff/isabella-buber-ennser/ 


\section{Appendix}

Fig. A1: Importance of one's own paid work for the decision to have a child during the next three years by employment status and satisfaction with job security and by making ends meet, men

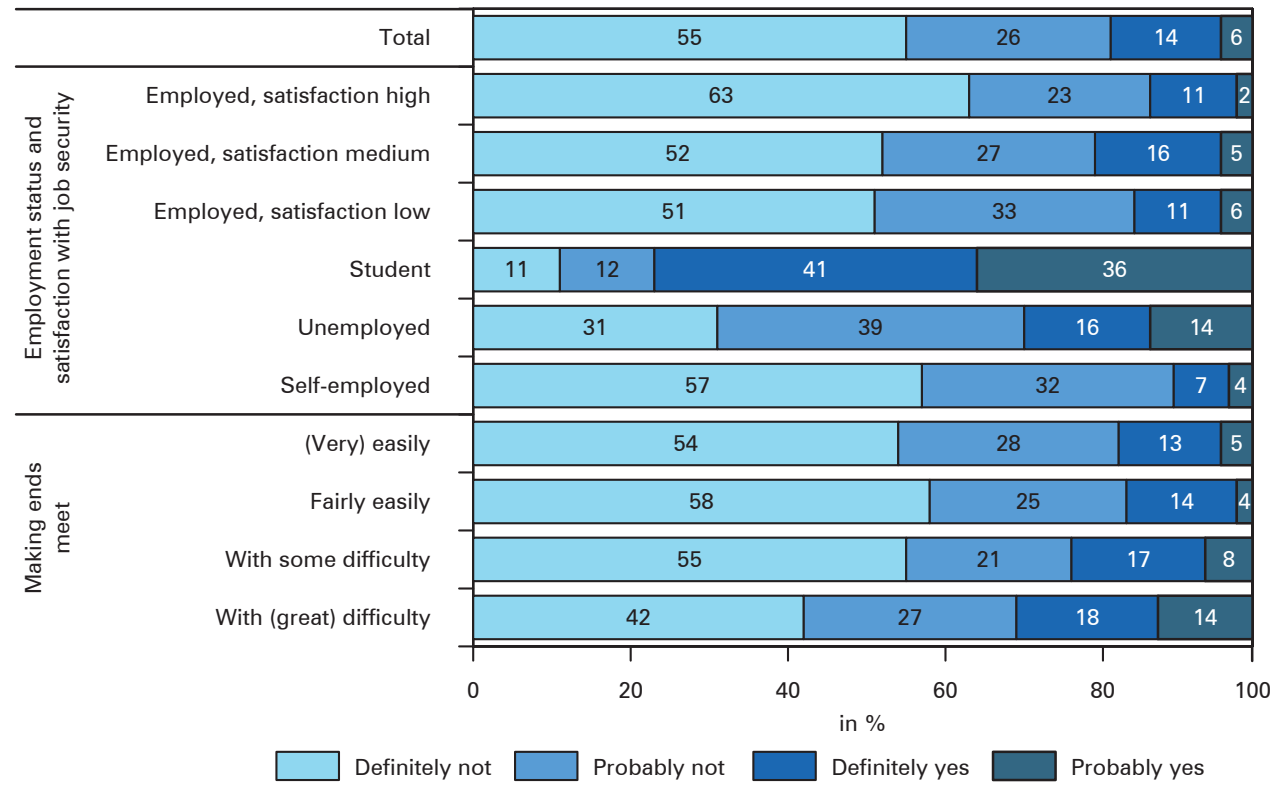

Note: Low satisfaction with job security (0-4 on 0-10-scale); medium satisfaction (5-8); high satisfaction (9-10).

The categories "leave", "housekeeping" and "other (employment status)" are not shown because of small numbers $(\mathrm{n}<30)$.

Source: Austrian GGS, 1,130 partnered men aged 18-44, weighted data 
Tab. A1: Distribution of variables for the analyses on intending a child within three years

\begin{tabular}{|c|c|c|c|}
\hline & All & Women & Men \\
\hline \multicolumn{4}{|l|}{ Employment status and satisfaction with job security } \\
\hline Self-employed & 241 & 120 & 121 \\
\hline Unemployed & 89 & 65 & 24 \\
\hline Student & 162 & 102 & 60 \\
\hline Leave & 221 & 220 & 1 \\
\hline Housekeeping & 156 & 155 & 1 \\
\hline Other & 50 & 20 & 30 \\
\hline Employed, low satisfaction with job security & 115 & 70 & 45 \\
\hline Employed, medium satisfaction with job security & 729 & 370 & 359 \\
\hline Employed, high satisfaction with job security & 1156 & 666 & 490 \\
\hline \multicolumn{4}{|l|}{ Concerns about making ends meet } \\
\hline With (great) difficulty & 214 & 148 & 66 \\
\hline With some difficulty & 490 & 285 & 205 \\
\hline Fairly easily & 1007 & 614 & 393 \\
\hline (Very) easily & 1206 & 739 & 467 \\
\hline \multicolumn{4}{|l|}{ Control variables } \\
\hline \multicolumn{4}{|l|}{ Parity } \\
\hline Childless & 1001 & 542 & 459 \\
\hline 1 child & 571 & 343 & 228 \\
\hline 2 children & 922 & 623 & 299 \\
\hline $3+$ children & 425 & 280 & 145 \\
\hline \multicolumn{4}{|l|}{ Age } \\
\hline 18-19 & 106 & 62 & 44 \\
\hline $20-24$ & 313 & 194 & 119 \\
\hline $25-29$ & 507 & 302 & 205 \\
\hline $30-34$ & 529 & 337 & 192 \\
\hline $35-39$ & 676 & 425 & 251 \\
\hline $40-44$ & 788 & 468 & 320 \\
\hline \multicolumn{4}{|l|}{ Education } \\
\hline Low (Ref.) & 1,821 & 1,059 & 762 \\
\hline Medium & 656 & 428 & 228 \\
\hline High & 442 & 301 & 141 \\
\hline \multicolumn{4}{|l|}{ Sex } \\
\hline Male (Ref.) & 1,129 & & \\
\hline Female & 1,786 & & \\
\hline Total & 2,917 & 1,786 & 1,129 \\
\hline
\end{tabular}

Source: Austrian GGS wave 1 
Tab. A2: Distribution of variables for realization of short-term fertility intentions

\begin{tabular}{|c|c|c|c|}
\hline & All & Women & Men \\
\hline \multicolumn{4}{|l|}{ Employment status and satisfaction with job security } \\
\hline Self-employed & 70 & 30 & 40 \\
\hline Unemployed & 22 & 14 & 8 \\
\hline Student & 29 & 20 & 9 \\
\hline Leave & 86 & 85 & 1 \\
\hline Housekeeping & 20 & 20 & 0 \\
\hline Other & 11 & 4 & 7 \\
\hline Employed, low satisfaction with job security & 50 & 30 & 20 \\
\hline Employed, medium satisfaction with job security & 213 & 95 & 118 \\
\hline Employed, high satisfaction with job security & 335 & 175 & 160 \\
\hline \multicolumn{4}{|l|}{ Concerns about making ends meet } \\
\hline With (great) difficulty & 54 & 39 & 15 \\
\hline With some difficulty & 124 & 69 & 55 \\
\hline Fairly easily & 290 & 165 & 125 \\
\hline (Very) easily & 368 & 200 & 168 \\
\hline \multicolumn{4}{|l|}{ Control variables } \\
\hline \multicolumn{4}{|l|}{ Parity } \\
\hline Childless & 471 & 252 & 219 \\
\hline 1 child & 241 & 145 & 96 \\
\hline 2 children & 90 & 61 & 29 \\
\hline $3+$ children & 34 & 15 & 19 \\
\hline \multicolumn{4}{|l|}{ Age } \\
\hline 18-19 & 16 & 12 & 4 \\
\hline $20-24$ & 118 & 80 & 38 \\
\hline $25-29$ & 287 & 169 & 118 \\
\hline $30-34$ & 216 & 120 & 96 \\
\hline $35-39$ & 127 & 65 & 62 \\
\hline $40-44$ & 72 & 27 & 45 \\
\hline \multicolumn{4}{|l|}{ Education } \\
\hline Low (Ref.) & 488 & 255 & 233 \\
\hline Medium & 186 & 113 & 73 \\
\hline High & 162 & 105 & 57 \\
\hline \multicolumn{4}{|l|}{ Sex } \\
\hline Male (Ref.) & 363 & & \\
\hline Female & 473 & & \\
\hline Total & 836 & 469 & 363 \\
\hline
\end{tabular}

Note: Variables refer to wave 1.

Source: Austrian GGS waves 1 and 2 


\section{Comparative Population Studies}

wWW.comparativepopulationstudies.de

ISSN: 1869-8980 (Print) - 1869-8999 (Internet)

\section{Published by}

Prof. Dr. Norbert F. Schneider

Federal Institute for Population Research D-65180 Wiesbaden / Germany

\section{(cc) BY-SA}

2017

\section{Managing Editor}

Frank Swiaczny

\section{Assistant Managing Editor}

Katrin Schiefer

\section{Copy Editor}

(Selected Articles in German)

Dr. Evelyn Grünheid

\section{Layout}

Beatriz Feiler-Fuchs

E-mail: cpos@bib.bund.de

\section{Scientific Advisory Board}

Paul Gans (Mannheim)

Karsten Hank (Cologne)

Johannes Huinink (Bremen)

Michaela Kreyenfeld (Rostock)

Marc Luy (Vienna)

Notburga Ott (Bochum)

Peter Preisendörfer (Mainz)

Nikola Sander (Groningen)

Zsolt Spéder (Budapest)

\section{Board of Reviewers}

Martin Abraham (Erlangen)

Laura Bernardi (Lausanne)

Hansjörg Bucher (Bonn)

Claudia Diehl (Konstanz)

Andreas Diekmann (Zurich)

Gabriele Doblhammer-Reiter (Rostock)

Jürgen Dorbritz (Wiesbaden)

Anette Eva Fasang (Berlin)

E.-Jürgen Flöthmann (Bielefeld)

Alexia Fürnkranz-Prskawetz (Vienna)

Beat Fux (Salzburg)

Joshua Goldstein (Berkeley)

Sonja Haug (Regensburg)

Hill Kulu (Liverpool)

Aart C. Liefbroer (The Hague)

Kurt Lüscher (Konstanz)

Emma Lundholm (Umeå)

Nadja Milewski (Rostock)

Dimiter Philipov (Vienna)

Roland Rau (Rostock)

Tomáš Sobotka (Vienna)

Jeroen Spijker (Barcelona)

Olivier Thévenon (Paris)

Helga de Valk (Brussels)

Heike Trappe (Rostock)

Michael Wagner (Cologne) 